\title{
Antiretroviral therapy for prevention of HIV transmission in HIV-discordant couples (Review)
}

\author{
Anglemyer A, Rutherford GW, Horvath T, Baggaley RC, Egger M, Siegfried N
}

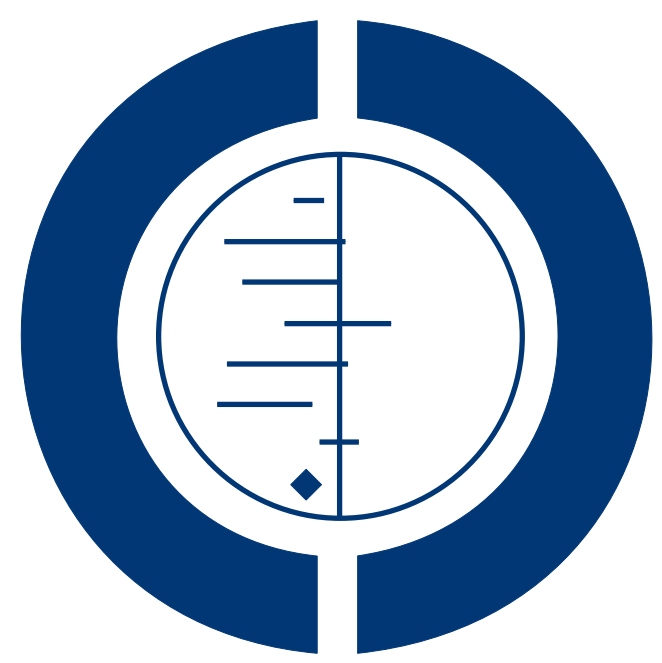

\section{THE COCHRANE COLLABORATION $^{\circledR}$}

This is a reprint of a Cochrane review, prepared and maintained by The Cochrane Collaboration and published in The Cochrane Library 2013, Issue 4

http://www.thecochranelibrary.com

\section{WILEY}


TABLE OF CONTENTS

HEADER . . . . . . . . . . . . . . . . . . . . . . . . . . . . . . . . . . . . . . . . . . . . . . . .

ABSTRACT . . . . . . . . . . . . . . . . . . . . . . . . . . . . . . . . . . . . . . . . . . .

PLAIN LANGUAGE SUMMARY . . . . . . . . . . . . . . . . . . . . . . . . . . . . . . . . . . . . . . . . . . . . .

SUMMARY OF FINDINGS FOR THE MAIN COMPARISON ．．．．．．．． . . . . . . . . . . . . . . . 3

BACKGROUND . . . . . . . . . . . . . . . . . . . . . . . . . . . . . . . . . . . . . . 5

OBJECTIVES . . . . . . . . . . . . . . . . . . . . . . . . . . . . . . . . . . . . . . . . . .

METHODS . . . . . . . . . . . . . . . . . . . . . . . . . . . . . . . . . . . . . .

Figure 1. . . . . . . . . . . . . . . . . . . . . . . . . . . . . . . . . . . . . . . . . .

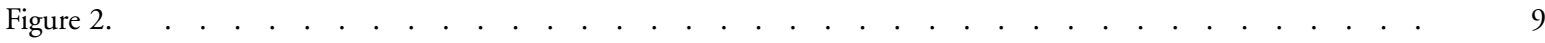

RESULTS . . . . . . . . . . . . . . . . . . . . . . . . . . . . . . . . . . . . . 10

Figure 3. . . . . . . . . . . . . . . . . . . . . . . . . . . . . . . . . . . . . . 11

Figure $4 . \quad$. . . . . . . . . . . . . . . . . . . . . . . . . . . . . . . . . . . . . . 13

Figure 5. . . . . . . . . . . . . . . . . . . . . . . . . . . . . . . . . . . . . .

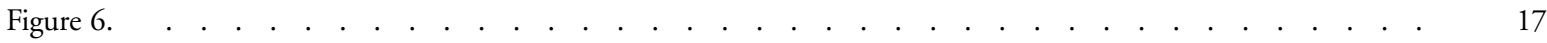

Figure $7 . \quad$. . . . . . . . . . . . . . . . . . . . . . . . . . . . . . . . . . . . . 17

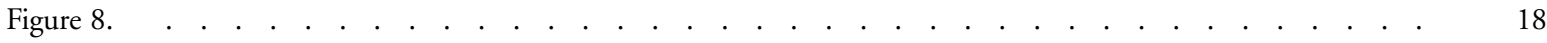

Figure 9. . . . . . . . . . . . . . . . . . . . . . . . . . . . . . . . . . . . . .

Figure 10. . . . . . . . . . . . . . . . . . . . . . . . . . . . . . . . . . . . . .

Figure 11. . . . . . . . . . . . . . . . . . . . . . . . . . . . . . . . . . . . . .

Figure 12. . . . . . . . . . . . . . . . . . . . . . . . . . . . . . . . . . . . . . . . 21

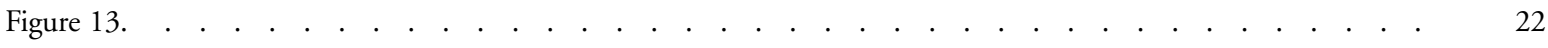

ADDITIONAL SUMMARY OF FINDINGS . . . . . . . . . . . . . . . . . . . . . . . . . . . . . . . .

DISCUSSION . . . . . . . . . . . . . . . . . . . . . . . . . . . . . . . . . . . . . . . . . .

Figure 14. . . . . . . . . . . . . . . . . . . . . . . . . . . . . . . . . . . . . . . . . . . 26

Figure 15. . . . . . . . . . . . . . . . . . . . . . . . . . . . . . . . . . . . . . . . . . . . . .

AUTHORS' CONCLUSIONS . . . . . . . . . . . . . . . . . . . . . . . . . . . . . . . . . . . . . . . . . . .

ACKNOWLEDGEMENTS . . . . . . . . . . . . . . . . . . . . . . . . . . . . . . . . . . . . . . . . . . .

REFERENCES . . . . . . . . . . . . . . . . . . . . . . . . . . . . . . . . . . . . . . . . . . . . .

CHARACTERISTICS OF STUDIES . . . . . . . . . . . . . . . . . . . . . . . . . . . . . . . . . . . . 31

DATA AND ANALYSES . . . . . . . . . . . . . . . . . . . . . . . . . . . . . . . . . . . . . . . . . . . . . . . . . . . . .

Analysis 1.1. Comparison 1 Delayed vs Immediate ART (RCTs), Outcome 1 Linked Incident HIV Infection. . . . . 41

Analysis 1.2. Comparison 1 Delayed vs Immediate ART (RCTs), Outcome 2 All Incident HIV Infection. . . . . . 42

Analysis 1.3. Comparison 1 Delayed vs Immediate ART (RCTs), Outcome 3 Severe or Life-Threatening Adverse Events

(Grade 3 or 4). . . . . . . . . . . . . . . . . . . . . . . . . . . . . . . . . . 42

Analysis 1.4. Comparison 1 Delayed vs Immediate ART (RCTs), Outcome 4 Grade 3 or 4 Laboratory Abnormalities. 43

Analysis 2.1. Comparison 2 Treated with ART vs Not Treated with ART (Observational Studies), Outcome 1 Incident HIV Infection.

Analysis 3.1. Comparison 3 Treated with ART vs Not Treated with ART (Observational Studies, sensitivity analysis),

Outcome 1 Incident HIV Infection.

Analysis 4.1. Comparison 4 Treated with ART vs Not Treated with ART $(<200,200-349$, and $\geq 350$ CD4 Cells/ $\mu \mathrm{L}$

Subgroup Analysis) (Observational Studies), Outcome 1 Incident HIV Infection.

Analysis 5.1. Comparison 5 Treated with ART vs Not Treated with ART (Female/Male Subgroup Analysis) (Observational

Studies), Outcome 1 Incident HIV Infection. . . . . . . . . . . . . . . . . . . . . . . . 47

Analysis 6.1. Comparison 6 Treated with ART vs Not Treated with ART (Subgroup Analysis: Low-/Middle-Income vs

High-income)) (Observational Studies), Outcome 1 Incident HIV Infection. . . . . . . . . . . . . 48

APPENDICES . . . . . . . . . . . . . . . . . . . . . . . . . . . . . . . . . . . . . . . . . .

WHAT'S NEW . . . . . . . . . . . . . . . . . . . . . . . . . . . . . . . . . . . . . . 52

HISTORY . . . . . . . . . . . . . . . . . . . . . . . . . . . . . . . . . . . . . . . . . 52

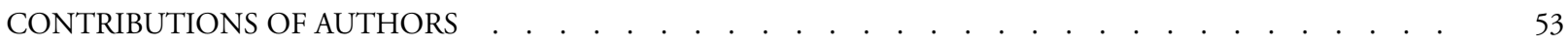

DECLARATIONS OF INTEREST . . . . . . . . . . . . . . . . . . . . . . . . . . . . . . . . . . . . . . .

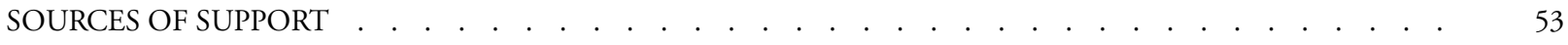

Antiretroviral therapy for prevention of HIV transmission in HIV-discordant couples (Review)

Copyright $\odot 2013$ The Cochrane Collaboration. Published by John Wiley \& Sons, Ltd. 
DIFFERENCES BETWEEN PROTOCOL AND REVIEW . . . . . . . . . . . . . . . . . . . . . . . . $\quad 53$

NOTES . . . . . . . . . . . . . . . . . . . . . . . . . . . . . . . . . . . . . . . . 53

INDEX TERMS . . . . . . . . . . . . . . . . . . . . . . . . . . . . . . . . . . . . . . . . . . . . 


\title{
[Intervention Review]
}

\section{Antiretroviral therapy for prevention of HIV transmission in HIV-discordant couples}

\author{
Andrew Anglemyer ${ }^{1}$, George W Rutherford ${ }^{1}$, Tara Horvath $^{1}$, Rachel C Baggaley ${ }^{2}$, Matthias Egger ${ }^{3}$, Nandi Siegfried ${ }^{4,5}$ \\ ${ }^{1}$ Global Health Sciences, University of California, San Francisco, San Francisco, California, USA. ${ }^{2}$ Department of HIV/AIDS, World \\ Health Organization, Geneva, Switzerland. ${ }^{3}$ Institute of Social Medicine, Institute of Social and Preventive Medicine, Bern, Switzerland. \\ ${ }^{4}$ Department of Psychiatry and Mental Health, Faculty of Health Sciences, University of Cape Town, Cape Town, South Africa. \\ ${ }^{5}$ Department of Epidemiology and Biostatistics, University of California, San Francisco, San Francisco, California, USA
}

Contact address: George W Rutherford, Global Health Sciences, University of California, San Francisco, San Francisco, California, 94105, USA. GRutherford@psg.ucsf.edu.

Editorial group: Cochrane HIV/AIDS Group.

Publication status and date: New search for studies and content updated (no change to conclusions), published in Issue 4, 2013.

Review content assessed as up-to-date: 26 February 2013.

Citation: Anglemyer A, Rutherford GW, Horvath T, Baggaley RC, Egger M, Siegfried N. Antiretroviral therapy for prevention of HIV transmission in HIV-discordant couples. Cochrane Database of Systematic Reviews 2013, Issue 4. Art. No.: CD009153. DOI: 10.1002/14651858.CD009153.pub3.

Copyright (C) 2013 The Cochrane Collaboration. Published by John Wiley \& Sons, Ltd.

\section{A B S T R A C T}

\section{Background}

Antiretroviral drugs have been shown to reduce risk of mother-to-child transmission of human immunodeficiency virus (HIV) and are also widely used for post-exposure prophylaxis for parenteral and sexual exposures. Sexual transmission may be lower in couples in which one partner is infected with HIV and the other is not and the infected partner is on antiretroviral therapy (ART).

\section{Objectives}

To determine if ART use in an HIV-infected member of an HIV-discordant couple is associated with lower risk of HIV transmission to the uninfected partner compared to untreated discordant couples.

\section{Search methods}

We used standard Cochrane methods to search electronic databases and conference proceedings with relevant search terms without limits to language.

\section{Selection criteria}

Randomised controlled trials (RCT), cohort studies and case-control studies of HIV-discordant couples in which the HIV-infected member of the couple was being treated or not treated with ART

\section{Data collection and analysis}

Abstracts of all trials identified by electronic or bibliographic scanning were examined independently by two authors. We initially identified 3,833 references and examined 87 in detail for study eligibility. Data were abstracted independently using a standardised abstraction form.

Antiretroviral therapy for prevention of HIV transmission in HIV-discordant couples (Review)

Copyright @ 2013 The Cochrane Collaboration. Published by John Wiley \& Sons, Ltd. 


\section{Main results}

One RCT and nine observational studies were included in the review. These ten studies identified 2,112 episodes of HIV transmission, 1,016 among treated couples and 1,096 among untreated couples. The rate ratio for the single randomised controlled trial was 0.04 [95\% CI 0.00, 0.27]. All index partners in this study had CD4 cell counts at baseline of 350-550 cells/ $\mu \mathrm{L}$. Similarly, the summary rate ratio for the nine observational studies was 0.58 [95\% CI $0.35,0.96]$, with substantial heterogeneity $\left(\mathrm{I}^{2}=64 \%\right)$. After excluding two studies with inadequate person-time data, we estimated a summary rate ratio of 0.36 [95\% CI 0.17, 0.75] with substantial heterogeneity $\left(\mathrm{I}^{2}=62 \%\right)$. We also performed subgroup analyses among the observational studies to see if the effect of ART on prevention of HIV differed by the index partner's CD4 cell count. Among couples in which the infected partner had $\geq 350 \mathrm{CD} 4 \mathrm{cells} / \mu \mathrm{L}$, we estimated a rate ratio of 0.12 [ $95 \%$ CI $0.01,1.99$ ]. In this subgroup, there were 247 transmissions in untreated couples and 30 in treated couples.

\section{Authors' conclusions}

ART is a potent intervention for prevention of HIV in discordant couples in which the index partner has $\leq 550 \mathrm{CD} 4 \mathrm{cells} / \mu \mathrm{L}$. A recent multicentre RCT confirms the suspected benefit seen in earlier observational studies and reported in more recent ones. Questions remain about durability of protection, the balance of benefits and adverse events associated with earlier therapy, long-term adherence and transmission of ART-resistant strains to partners. Resource limitations and implementation challenges must also be addressed.

Counselling, support, and follow up, as well as mutual disclosure, may have a role in supporting adherence, so programmes should be designed with these components. In addition to ART provision, the operational aspects of delivering such programmes must be considered.

\section{PLAIN LANGUAGE SUMMARY}

\section{Antiretroviral therapy for prevention of HIV transmission in HIV-discordant couples}

Antiretroviral drugs can prevent transmission of HIV from an infected sexual partner to an uninfected one, by suppressing viral replication. We found one randomised controlled trial and nine observational studies that examined this question. Overall we found that in couples in which the infected partner was being treated with antiretroviral drugs the uninfected partners had, at worst, more than $40 \%$ lower risk of being infected than in couples where the infected partner was not receiving treatment. Since the World Health Organization (WHO) already recommends antiretroviral treatment for all persons with $\leq 350 \mathrm{CD} 4$ cells/ $\mu \mathrm{L}$, we also examined studies that had studied couples in which the infected partners had CD4 counts higher than this level. We found that there is strong evidence from the randomised controlled trial that in this group HIV was less likely to be transmitted to uninfected partners from treated infected partners than from untreated infected partners. 


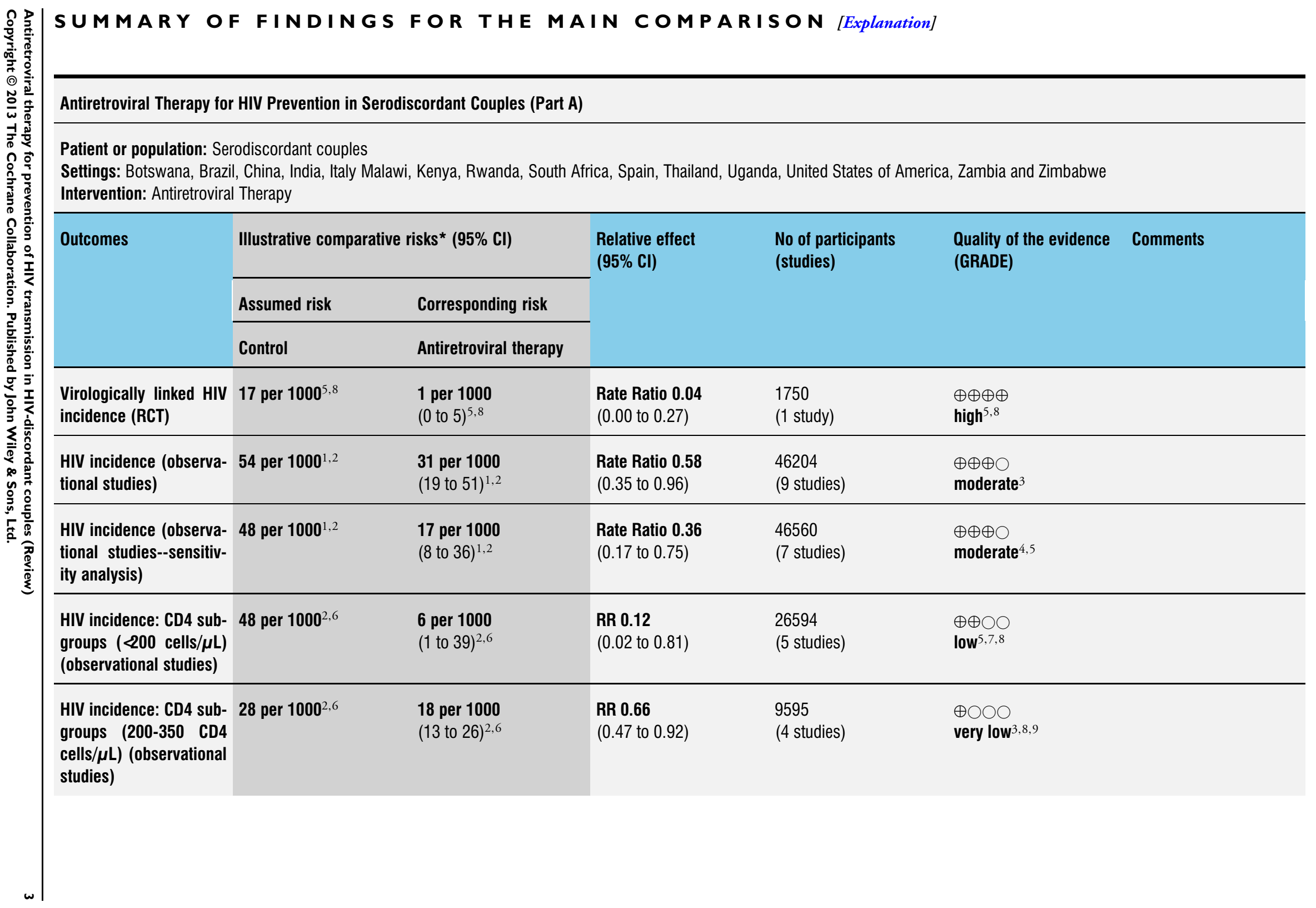




$\begin{array}{llll} & & & \\ \end{array}$

*The basis for the assumed risk (e.g. the median control group risk across studies) is provided in footnotes. The corresponding risk (and its $95 \%$ confidence interval) is based on the assumed risk in the comparison group and the relative effect of the intervention (and its $95 \% \mathrm{Cl}$ ).

RCT: randomised controlled trial; Cl: confidence interval; RR: risk ratio.

\section{GRADE Working Group grades of evidence}

High quality: Further research is very unlikely to change our confidence in the estimate of effect.

Moderate quality: Further research is likely to have an important impact on our confidence in the estimate of effect and may change the estimate.

Low quality: Further research is very likely to have an important impact on our confidence in the estimate of effect and is likely to change the estimate.

Very low quality: We are very uncertain about the estimate.

${ }^{1}$ Less than $5 \%$ of sample was imputed due to missing information in the denominator.

${ }^{2}$ Numerators and Denominators taken from text where possible. Numbers were not used to calculate the relative effect estimates.

Rate Ratio $\sim 0.50$

है Two studies were removed due to differences in intervention or incomplete data.

${ }^{5} \mathrm{RR}<0.35$

${ }^{6}$ Due to missing information in the denominator and/or numerator, some data were imputed from text.

${ }^{7}$ No person time available for 3 out of 5 studies.

${ }^{8}$ Few events and/or wide confidence interval.

${ }^{9}$ No person time available for 2 out of 4 studies.

${ }^{10}$ No person time available for 1 out of 3 studies. 


\section{B A C K G R O U N D}

Antiretroviral drugs have been shown to reduce risk of motherto-child transmission of human immunodeficiency virus (HIV) (Siegfried 2011), and are widely used for post-exposure prophylaxis for parenteral and sexual exposures (Young 2007, Grant 2010), although these indications have not been examined in randomised controlled trials (RCT) (Young 2007). They are also efficacious in preventing acquisition of HIV infection by uninfected individuals (pre-exposure prophylaxis) (Okwundu 2012). Sexual transmission is lower in couples in which one partner is infected with HIV and the other is not and the infected partner is on antiretroviral therapy (ART) (Anglemyer 2011b), and models indicate widespread prevention benefit if large numbers of infected patients in a population are treated (Granich 2009). Ecological studies from Taiwan (Fang 2004), British Columbia (Wood 2009, Gill 2010, Montaner 2010) and San Francisco (Porco 2004, Das 2010) have found that transmission has decreased as the proportion of treated patients increases and community viral load decreases (Das 2010).

In a cohort analysis of couples followed in a trial of sexually transmitted disease control for prevention of HIV in the era before ART was widely available in rural Africa, risk of sexual transmission in discordant couples was lowest in couples in which the infected partner had an HIV serum viral load of $<400$ copies/mL (Quinn 2000). Similarly, data from trials and cohort studies of mother-tochild transmission of HIV have demonstrated that mothers with the lowest viral loads are the least likely to transmit (Jourdain 2007). While plasma (or serum in the case of Quinn 2000) viral loads do not necessarily directly correlate with viral loads in semen or cervico-vaginal secretions and HIV can continue to be shed despite non-detectable plasma viral loads (Sheth 2009), the absence of detectable HIV RNA in plasma roughly corresponds to lower levels of HIV RNA in genital tract secretions (Vettore 2006, Lorella 2009). Moreover, a recently published simulation model aimed to estimate the risk of HIV transmission, in the context of condom use, from homosexual men treated with ART to their partners (Hallett 2011) and found that, even when never using condoms with long-term partners, the predicted risk of transmission to long-term partners was only $22 \%$.

Taken together this body of literature suggests that treating an infected individual with ART may decrease the risk of sexual transmission to his or her uninfected partners. In this review we examine whether treating an HIV-infected partner (or "index" partner) with ART is associated with decreased risk of acquiring HIV in an uninfected member of a discordant couple.

\section{Description of the condition}

HIV infection is a chronic retroviral infection of humans that is almost universally fatal if left untreated. HIV can be transmitted sexually, parenterally or perinatally; globally sexual transmission accounted for about $70 \%$ of the 2.7 million new HIV infections in 2008 (UNAIDS 2009). Data from Africa suggest that more than half of new infections are occurring in stable couples who are serodiscordant for HIV infection, meaning that one member of the couple is infected and the other is not (Dunkle 2008, Mermin 2008).

\section{Description of the intervention}

Use of any antiretroviral drugs alone or in combination in HIVinfected members of discordant couples.

Inclusion criteria:

- Randomised controlled trial (RCT), cohort study or casecontrol study

- Compares HIV-discordant couples in which the HIVinfected member is treated or not treated

- Provides sufficient regimen-specific information about drugs to compare regimens and outcomes of interest

\section{Exclusion criteria:}

- Studies in which all HIV-infected members of discordant couples are either all treated or all not treated

- Letter, editorial, non-systematic review, case report, case series, cross-sectional study

\section{How the intervention might work}

By suppressing HIV replication systemically and decreasing HIV shedding in the genital tract.

\section{Why it is important to do this review}

If there is, indeed, prevention benefit from ART, in addition to its well-established therapeutic efficacy, the weight of evidence may shift to treating infected patients earlier in the course of their infection than is currently recommended (WHO 2010).

\section{O B J E C T I VES}

To assess if ART is associated with decreased risk of HIV transmission from an infected sexual partner to an uninfected sexual partner. Additionally, this review aims to assess specifically if ART in a patient with $\geq 350 \mathrm{CD} 4$ cells $/ \mu \mathrm{L}$ is also associated with a lowered risk of HIV transmission.

\section{METHODS}




\section{Criteria for considering studies for this review}

\section{Types of studies}

RCTs, cohort studies and case-control studies that included data and analysis for the comparison of interest.

\section{Types of participants}

HIV-discordant couples that is, stable sexual partnerships in which one member is infected with HIV and the other uninfected. Studies with heterosexual or homosexual couples were eligible for inclusion.

\section{Types of interventions}

Use of any antiretroviral drugs alone or in combination in HIVinfected members of discordant couples. Variations of interest included patients receiving HIV monotherapy, those receiving dual therapy and those receiving the current standard of three or more antiretroviral drugs (Jourdain 2007).

\section{Types of outcome measures}

\section{Primary outcomes}

- Incident HIV Infection

- Incident HIV Infection with viral isolates matched from index patient to newly infected partner

\section{Secondary outcomes}

- Acquisition of primary drug-resistant HIV. This is defined as an incident infection with an HIV strain resistant to one or more standard antiretroviral drugs.

- Severe adverse events in participants receiving treatment (Grade IV and life-threatening)

\section{Search methods for identification of studies}

See search methods used in reviews by the Cochrane Collaborative Review Group on HIV Infection and AIDS.

\section{Electronic searches}

We formulated a comprehensive and exhaustive search strategy in an attempt to identify all relevant studies regardless of language or publication status (published, unpublished, in press and in progress). Full details of the Cochrane HIV/AIDS Review Group methods and the journals hand-searched are published in the section on Collaborative Review Groups in The Cochrane Library. Journal and trials databases
We searched the following electronic databases, in the period from 01 January 1987 to 31 August 2012:

- PubMed

- EMBASE

- Cochrane Central Register of Controlled Trials (CENTRAL)

- Web of Science

- LILACS

Along with $\mathrm{MeSH}$ terms and relevant keywords, we used the Cochrane Highly Sensitive Search Strategy for identifying reports of RCTs in MEDLINE (Higgins 2008), and the Cochrane HIV/ AIDS Group's existing strategies for identifying references relevant to HIV/AIDS. The search strategy was iterative, in that references of included studies were searched for additional references. All languages were included. See Appendix 1 for example of our PubMed search strategy, which was modified as appropriate for use in the other databases. In searching conference abstract archives, it was not possible to perform complex searches. Instead, we used a variety of relevant terms, individually and in simple combinations. See Appendix 2 for these terms, and the yields from these searches. Using a variety of relevant terms, we also searched the clinical trials registry at the US National Institutes of Health's ClinicalTrials.gov (www.clinicaltrials.gov).

Limits. The searches were performed without limits to language or setting and limited to human studies published from 1987 (start of the antiretroviral era) to the present.

\section{Searching other resources}

\section{Conference abstract databases}

Using a variety of relevant terms, we searched the Aegis archive of HIV/AIDS conference abstracts (www.aegis.org), which includes the following conferences:

- British HIV/AIDS Association, 2001-2008

- Conference on Retroviruses and Opportunistic Infections (CROI), 1994-2008

- European AIDS Society Conference, 2001 and 2003

- International AIDS Society, Conference on HIV

Pathogenesis, Treatment and Prevention (IAS), 2001-2005

- International AIDS Society, International AIDS

Conference (IAC), 1985-2004

- US National HIV Prevention Conference, 1999, 2003, and 2005

We also searched the CROI and International AIDS Society web sites for abstracts presented at conferences subsequent to those listed above (CROI, 2009-2012; IAC, 2006-2012; IAS, 2007 2011).

Researchers and relevant organizations. We contacted individual researchers working in the field, such as the AIDS Clinical Trials Group, and policymakers based in inter-governmental organi- 
zations including the Joint United Nations Programme on HIV/ AIDS (UNAIDS) and WHO to identify studies either completed or ongoing.

Reference lists. We checked the reference lists of all studies identified by the above methods and examined the bibliographies of any systematic reviews, meta-analyses, or current guidelines we identified during the search process.

\section{Data collection and analysis}

The methodology for data collection and analysis was based on the guidance of Cochrane Handbook of Systematic Reviews of Interventions (Higgins 2008). Abstracts of all trials identified by electronic or bibliographic scanning were examined by two authors (AA and GWR) working independently. Where necessary, the full text was obtained to determine the eligibility of studies for inclusion.

\section{Selection of studies}

After removing duplicate references, One author (TH) made the first broad cut of these results, excluding those that were clearly irrelevant (e.g. animal studies, editorials, paediatric studies, studies without HIV endpoints).

Two authors (AA and GWR) then independently selected potentially relevant studies by scanning the titles, abstracts, and descriptor terms of the remaining references and applied the inclusion criteria. Irrelevant reports were discarded, and the full article or abstract was obtained for all potentially relevant or uncertain reports. The two authors independently applied the inclusion criteria. Studies were reviewed for relevance, based on study design, types of participants, exposures and outcomes measures. A neutral third party was available to adjudicate any disagreements that could not have been resolved by discussion.

\section{Data extraction and management}

After initial search and article screening, two reviewers independently double-coded and entered information from each selected study onto standardised data extraction forms. Extracted information included:

- Study details: citation, start and end dates, location, study design and details.

- Participant details: study population eligibility (inclusion and exclusion) criteria, ages, population size, attrition rate, details of HIV diagnosis and disease and any clinical, immunologic or virologic staging or laboratory information on the infected partner.

- Interventions details: Drug names, doses, duration and any other information on adherence or resistance.

- Outcome details: Incident HIV infection in the uninfected partner, acquisition of a drug-resistant strain of HIV

\section{Assessment of risk of bias in included studies}

We used the Cochrane Collaboration tool for assessing the risk of bias for each individual study and present results in a summary table (Figure 1). For trials, the Cochrane tool assesses risk of bias in individual studies across six domains: sequence generation, allocation concealment, blinding, incomplete outcome data, selective outcome reporting and other potential biases.

Figure I. Risk of bias graph: review authors' judgements about each risk of bias item presented as percentages across all included studies.

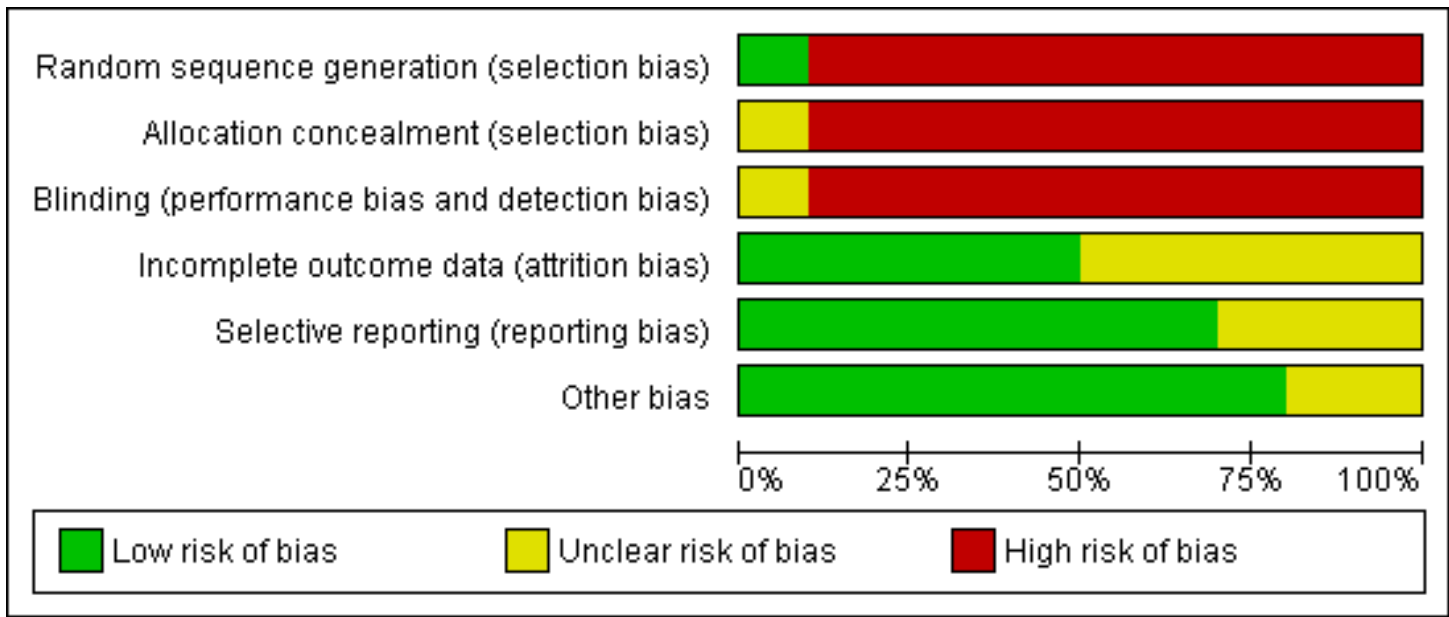

Antiretroviral therapy for prevention of HIV transmission in HIV-discordant couples (Review) 


\section{Sequence generation}

- Adequate: investigators described a random component in the sequence generation process, such as the use of random number table, coin tossing, card or envelope shuffling, etc.

- Inadequate: investigators described a non-random component in the sequence generation process, such as the use of odd or even date of birth, algorithm based on the day or date of birth, hospital, or clinic record number.

- Unclear: insufficient information to permit judgement of the sequence generation process.

\section{Allocation concealment}

- Adequate: participants and the investigators enrolling participants cannot foresee assignment (e.g., central allocation; or sequentially numbered, opaque, sealed envelopes).

- Inadequate: participants and investigators enrolling participants can foresee upcoming assignment (e.g., an open random allocation schedule, a list of random numbers); or envelopes were unsealed or non-opaque or not sequentially numbered.

- Unclear: insufficient information to permit judgement of the allocation concealment or the method not described.

\section{Blinding}

- Adequate: blinding of the participants, key study personnel, and outcome assessor, and unlikely that the blinding could have been broken. No blinding in the situation where non-blinding is not likely to introduce bias.

- Inadequate: no blinding or incomplete blinding when the outcome is likely to be influenced by lack of blinding.

- Unclear: insufficient information to permit judgement of adequacy or otherwise of the blinding.

\section{Incomplete outcome data}

- Adequate: no missing outcome data, reasons for missing outcome data unlikely to be related to true outcome, or missing outcome data balanced in number across groups.

- Inadequate: reason for missing outcome data likely to be related to true outcome, with either imbalance in number across groups or reasons for missing data.

- Unclear: insufficient reporting of attrition or exclusions.

\section{Selective reporting}

- Adequate: a protocol is available which clearly states the primary outcome as the same as in the final trial report.

- Inadequate: the primary outcome differs between the protocol and final trial report.

- Unclear: no trial protocol is available or there is insufficient reporting to determine if selective reporting is present.

\section{Other forms of bias}

- Adequate: there is no evidence of bias from other sources.

- Inadequate: there is potential bias present from other sources (e.g., early stopping of trial, fraudulent activity, extreme baseline imbalance, or bias related to specific study design).

- Unclear: insufficient information to permit judgement of adequacy or otherwise of other forms of bias.

We used the Newcastle-Ottawa Scale (Newcastle-Ottawa) to assess the quality and risk of bias in non-randomised studies. Specifically, the scale uses a star system to judge three general areas: selection of study groups, comparability of groups, and ascertainment of outcomes (in the case of cohort studies). As a result, this instrument can assess the quality of non-randomised studies so that they can be used in a meta-analysis or systematic review. Please see Figure 2 and Appendix 3 for details. 
Figure 2. Newcastle-Ottawa Scale for Bias Assessment

Summary of critical appraisal of included studies using the Newcastle-Ottawa Quality Assessment Scale for cohort studies

\begin{tabular}{|l|l|l|l|}
\hline Study ID & $\begin{array}{l}\text { Selection } \\
\text { (max 4 stars) }\end{array}$ & $\begin{array}{l}\text { Comparability } \\
\text { (max 2 stars) }\end{array}$ & $\begin{array}{l}\text { Outcome } \\
\text { (max 3 stars) }\end{array}$ \\
\hline Birungi et al (2012) & $* * * *$ & -- & $* *$ \\
\hline Jia et al (2012) & $* * * *$ & $*$ & $* *$ \\
\hline Del Romero et al (2010) & $* * * *$ & -- & $* * *$ \\
\hline Donnell et al (2010) & $* * * *$ & $*$ & $* * *$ \\
\hline Wang et al (2010) & $* * * *$ & -- & $* *$ \\
\hline Reynolds et al (2009) & $* * * *$ & -- & $* *$ \\
\hline Sullivan et al (2009) & $* * * *$ & $*$ & $* *$ \\
\hline Melo et al (2008) & $* * * *$ & -- & $* * *$ \\
\hline Musicco et al (1994) & $* * * *$ & $*$ & $* * *$ \\
\hline
\end{tabular}

Selection

1) Representativeness of intervention cohort-a] Truly representative of average, treated serodiscordant couple*; b] somewhat representative of average, treated, serodiscordant couple*; c] only selected group of patients; no description of derivation of cohort

2) Selection of non intervention cohort-a] drawn from same community as intervention cohort*; b] drawn from different source; c] no description of the derivation of the non intervention cohort

3) Ascertainment of intervention-a] health record*; b] structured interview*; c] written self-report; d] no description

4) Demonstration that outcome was not present at start of study-a] yes*; b] no

Comparability

1) Comparability of cohorts on basis of design or analysis-a] study controls for age, sex, or frequency of sex*; b] study controls for any additional factors*

Outcome

1) Assessment of outcome-a] independent blind assessment*; b] record linkage*; c] self report; d] no description

2) Was follow up long enough for outcomes to occur-a] yes (median duration of follow up $>6$ months); b] no

3) Adequacy of follow up of cohort-a] complete follow up*; b] minimal loss to follow up ( $<=20 \%$ ); c] follow up rate $<80 \%$

and no description of losses to follow up; d] no statement

\section{Assessment of Quality of Evidence Across Studies}

We assessed the quality of evidence across a body of evidence (i.e., multiple studies with similar interventions and outcomes) with the GRADE approach (Guyatt 2008), defining the quality of evidence for each outcome as "the extent to which one can be confident that an estimate of effect or association is close to the quantity of specific interest" (Higgins 2008). The quality rating across studies has four levels: high, moderate, low or very low. RCTs are categorised as high quality but can be downgraded; similarly, other types of controlled trials and observational studies are categorised as low quality but can be upgraded. Factors that decrease the quality of evidence include limitations in design, indirectness of evidence, unexplained heterogeneity or inconsistency of results, imprecision of results or high probability of publication bias. Factors that can increase the quality level of a body of evidence include a large magnitude of effect, if all plausible confounding would lead to an underestimation of effect and if there is a dose-response gradient. See Summary of findings for the main comparison and Summary of findings 2 .

\section{Measures of treatment effect}

We used Review Manager 5 provided by the Cochrane Collaboration for statistical analysis and GRADEpro software (GRADEpro 2008) to produce GRADE Summary of Findings tables and GRADE evidence profiles. We summarised dichotomous outcomes for effect in terms of risk ratio (RR), rate ratio and number needed to treat (NNT) with their 95\% confidence intervals. Tests for interaction (i.e. Ratio of Risk Ratios, RRR) were performed to compare estimates within subgroups using methods described in Altman et al (Altman 2003).

We summarised rate data in terms of rate ratios with their $95 \%$ confidence intervals. Standard errors for each estimate were estimated using methods described in Rothman et al (Rothman 1998).

We calculated summary statistics using meta-analytic methods and present findings in GRADE Summary of Findings tables for all outcomes of interest. 


\section{Unit of analysis issues}

The unit of analysis was the individual partner in the discordant couple who was uninfected at baseline in each study.

\section{Dealing with missing data}

Study authors were contacted when missing data were an issue.

\section{Assessment of heterogeneity}

We examined heterogeneity among the observational studies using the $\chi^{2}$ statistic with a significance level of 0.10 , and the $\mathrm{I}^{2}$ statistic. We interpreted an $\mathrm{I}^{2}$ estimate greater than $50 \%$ as indicating moderate or high levels of heterogeneity and investigated its causes by sensitivity analysis. If heterogeneity persisted, we reported potential reasons for the observed heterogeneity.

\section{Assessment of reporting biases}

We assessed the potential for publication bias for the trial and for the observational studies using funnel plots. We attempted to minimise the potential for publication bias by our comprehensive search strategy that included evaluating published and unpublished literature.

\section{Data synthesis}

When interventions and study populations were sufficiently similar across the different observational studies, we pooled the data across studies and estimated summary effect sizes using both fixedand random-effects models. Specifically, we estimated the $\log$ (rate ratio) for each included study and used the inverse variance method to calculate study weights. The inverse variance method assumes that the variance for each study is inversely proportional to its importance, therefore more weight is given to studies with less variance than studies with greater variance.

We summarised the quality of evidence for the trial and the observational studies separately for each outcome for which data were available in GRADE Summary of Findings tables and GRADE evidence profiles (Guyatt 2008).

\section{Subgroup analysis and investigation of heterogeneity}

We performed sub-group analysis in the observational studies by baseline CD4 counts in index partners and by gender of index partners. Heterogeneity was explored using further sub-group analyses by setting (middle- or low- versus high-income country). A test for interaction was performed for each subgroup comparison.

\section{Sensitivity analysis}

As pooled results were heterogeneous for the observational studies, we conducted sensitivity analyses to identify studies with outlying results for further examination.

\section{RES U L T S}

\section{Description of studies}

See: Characteristics of included studies; Characteristics of excluded studies.

\section{Results of the search}

Searches for the first version of this review (Anglemyer 2011a) were conducted on February 1, 2011. The review was updated three months later (Anglemyer 2011b) after the data and safety monitoring board of a trial in progress (Cohen 2011) recommended that its findings be released ahead of schedule. Those findings were included in the review's second version (Anglemyer 2011b). Searches for the review's current version were conducted on August 31, 2012.

The searches on February 1, 2011 produced 1,483 titles after 331 duplicates were removed. After initial screening of titles by one author $(\mathrm{TH}), 237$ titles and abstracts were selected for further review by two authors (AA and GWR). AA and GWR independently conducted the selection of potentially relevant studies by scanning the titles, abstracts, and descriptor terms of all downloaded material from the electronic searches. Irrelevant reports were discarded, and the full article was obtained for all potentially relevant or uncertain reports. AA and GWR independently applied the inclusion criteria. NS acted as arbiter where there was disagreement. Studies were reviewed for relevance, based on study design, types of participants, exposures and outcomes measures. Finally, where resolution was not possible because further information was required, the study was allocated to the list of those awaiting assessment. Twenty-three full-text articles were closely examined by two authors (AA and GWR). In the review's initial publication (Anglemyer 2011a), seven observational studies were included. The second version (Anglemyer 2011b) added RCT data from Cohen 2011. It thus included one RCT and seven observational studies. See Figure 3 for a flowchart of the screening process for Anglemyer 2011b. 
Figure 3. Screening process, PREVIOUS version of the review (Anglemyer 20 I lb)

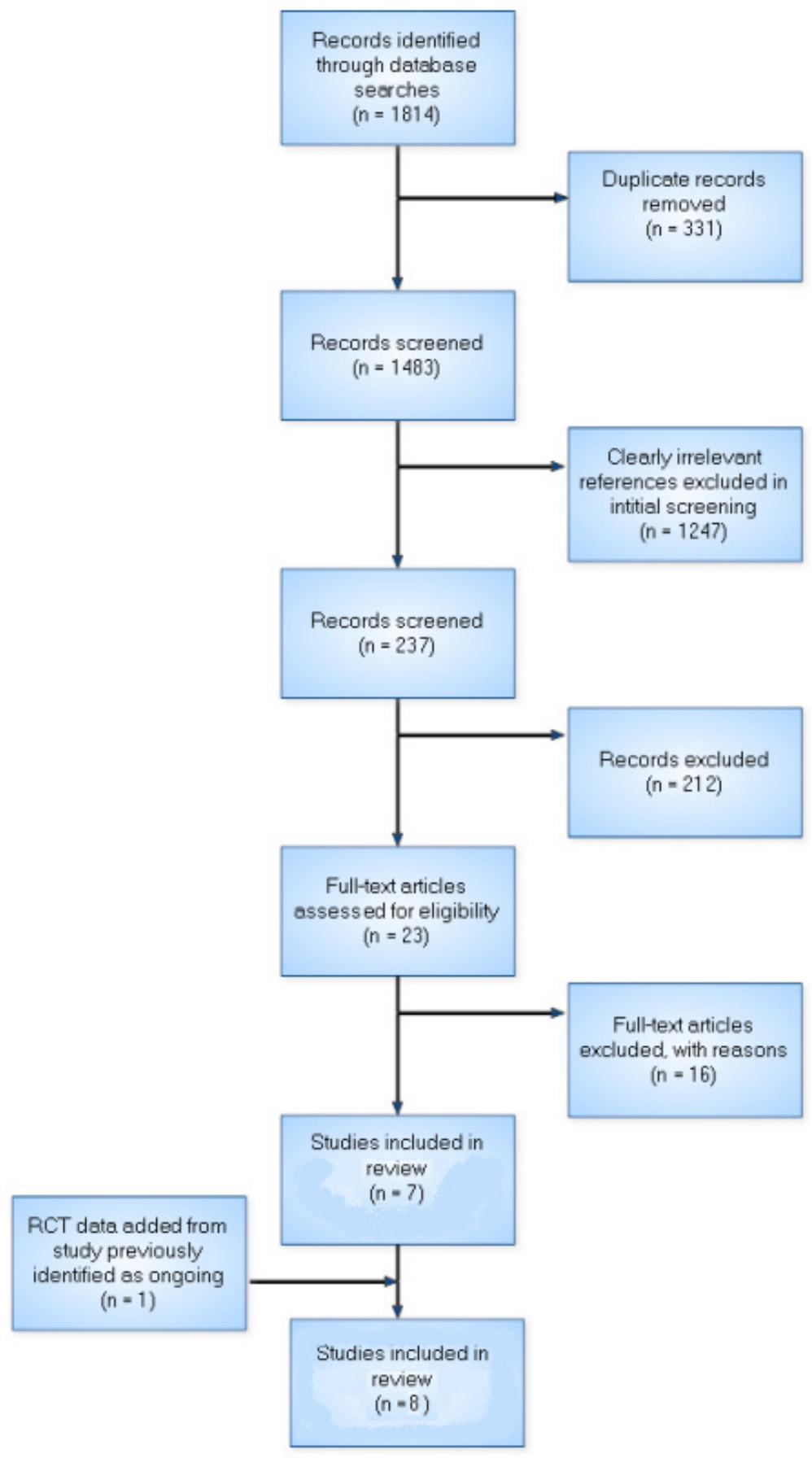


The searches on August 31, 2012 produced 2,350 titles after 720 duplicates were removed. After initial screening of titles by one author $(\mathrm{TH}), 882$ titles and abstracts were selected for further review by two authors (AA and GWR). AA and GWR independently conducted the selection of potentially relevant studies by scanning the titles, abstracts, and descriptor terms of all downloaded material from the electronic searches. Irrelevant reports were discarded, and the full article was obtained for all potentially relevant or uncertain reports. AA and GWR independently applied the inclusion criteria. $\mathrm{TH}$ acted as arbiter where there was disagreement.
Studies were reviewed for relevance, based on study design, types of participants, exposures and outcomes measures. Finally, where resolution was not possible because further information was required, the study was allocated to the list of those awaiting assessment. Sixty-four full-text articles were closely examined by two authors (AA and GWR). Two new cohort studies were identified. In the current review, one RCT and nine cohort studies met our inclusion criteria for data extraction, coding and potential metaanalysis. See Figure 4 for a flowchart of the screening process for the current review. 
Figure 4. Screening process, CURRENT version of the review.

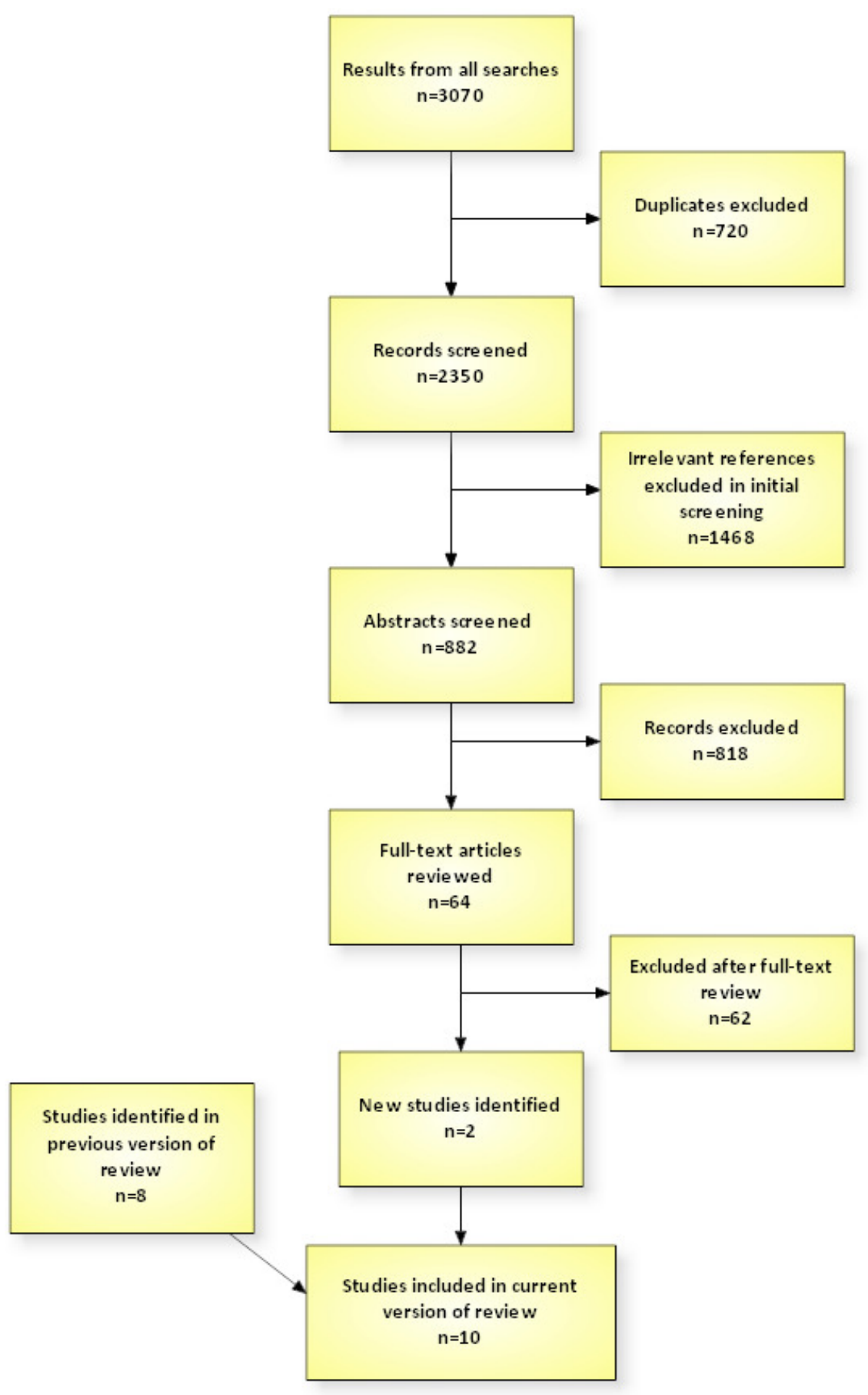




\section{Included studies}

The RCT was conducted in nine countries: Botswana, Brazil, India, Malawi, Kenya, South Africa, Thailand, United States of America and Zimbabwe (Cohen 2011). This trial mostly included heterosexual partners, but 3\% homosexual partners were also included. The nine included cohort studies were conducted in Italy (Musicco 1994), Brazil (Melo 2008), Zambia and Rwanda (Sullivan 2009), Uganda (Reynolds 2011, Birungi 2012), Spain (Del Romero 2010), China (Lu 2010, Jia 2012) and Botswana, Kenya, Rwanda, South Africa, Tanzania, Uganda, and Zambia (Donnell 2010). Two studies appeared both in abstract and print form (Del Romero 2010, Donnell 2010). Six of the nine observational studies were of partners of persons infected heterosexually (Musicco 1994, Sullivan 2009, Donnell 2010, Lu 2010, Reynolds 2011, Birungi 2012), one was of partners in either heterosexual or same-sex relationships (Jia 2012), and two were predominantly of heterosexual partners of injection drug users (Melo 2008, Del Romero 2010). In eight observational studies (Melo 2008, Sullivan 2009, Del Romero 2010, Donnell 2010, Lu 2010, Reynolds 2011, Birungi 2012, Jia 2012) infected partners received three or more antiretroviral drugs, and in one early study they received zidovudine (AZT) monotherapy only (Musicco 1994).

Musicco 1994: Musicco and colleagues conducted a cohort study in Italy, which was published in 1994 in the era before the advent of combination ART. They followed a cohort of 436 monogamous HIV-uninfected female sexual partners of HIV-infected men recruited from 16 centres in Italy. Seventy-nine percent of the male index patients had histories of injection drug use, $25 \%$ had symptoms of AIDS, and $48 \%$ had fewer than $400 \mathrm{CD} 4$ cells $/ \mu \mathrm{L}$. There were 27 seroconversions observed, 21 in partners of men who were not receiving AZT monotherapy and 6 in partners of men who were. Incidence in the untreated group was 4.4 per 100 person years $(95 \%$ confidence interval $[\mathrm{CI}] 2.6-5.7)$ and 3.8 (95\% CI 1.4-8.3) in the treated group (unadjusted rate ratio $0.88,95 \% \mathrm{CI}$ $0.36-2.16$ ). However, when adjusted for consistent condom use, presence of $\mathrm{p} 24$ antigen, CD4 counts and symptoms of AIDS in infected male partners, the relative risk of female partners of men treated with AZT acquiring HIV was 50\% lower (RR 0.5, 95\% CI 0.1-0.9) when compared to female partners of men not treated with AZT.

Melo 2008: Melo and colleagues followed a cohort of 93 discordant couples in Porto Alegre, Brazil, in which the female member of the couple was infected in $67(72 \%)$ and the male in $26(28 \%)$. Fifteen $(58 \%)$ of the 26 male and $6(9 \%)$ of the female index cases had histories of injection drug use. Of the 26 male index cases, $5(19 \%)$ had CD4 counts $<350$ cells $/ \mu \mathrm{L}$; of the 67 female index cases, $3(5 \%)$ had $<350 \mathrm{CD} 4$ cells/ $\mu \mathrm{L}$, and 33 (49\%) were pregnant at baseline. Comparing treated to untreated serodiscordant couples, their results suggest a protective effect of ART (rate ratio= 0.10; 95\% CI 0.01-1.67).

Sullivan 2009: Sullivan and colleagues presented data from two cohorts of 2,993 HIV-discordant couples in Rwanda and Zambia followed from 2002 to 2008 . No additional background data on cohort members were available from the conference abstract. They observed 175 new infections of which 4 were from partners of index cases on ART. Incidence density was $3.4 \%$ per 100 personyears for those whose partners were not taking ART and $0.7 \%$ for those whose partners were taking ART (rate ratio= $0.21,95 \%$ CI 0.08-0.59). An earlier abstract also reported on this cohort (Kayitenkore 2006).

Del Romero 2010: Del Romero and colleagues analysed data from 648 heterosexual couples attending a clinic in Madrid, Spain, from 1989 to 2008, where uninfected partners were examined for prevalent HIV infection. Five hundred thirty-five (83\%) of the index cases were male and 113 (17\%) female. Of the 648 index cases, 494 (76\%) had histories of injection drug use. Median CD4 count was 500 cells $/ \mu \mathrm{L}$. Clinical AIDS had been diagnosed at baseline in $107(17 \%)$ of index cases. Forty-six partners were found to have prevalent HIV infection when examined prior to follow-up. Forty-four of these occurred in partners of index cases who had received no ART, and 2 were in partners of index cases who had received either monotherapy or dual therapy. Four hundred twentyfour serodiscordant couples had follow-up information collected over 1355 couple years. Five transmission events occurred in untreated couples over 863 couple years, and no transmissions occurred among treated couples over 492 couple years (rate ratio $0.21 ; 95 \%$ CI 0.01-3.75). Earlier studies also analysed this cohort (Castilla 2005).

Donnell 2010: Donnell and colleagues reported data in an abstract from a prospective cohort analysis of an RCT of heterosexual African adults who were seropositive for both HIV and herpes simplex virus type 2 (HSV-2) and their HIV-uninfected sexual partners. Three thousand four hundred eight couples were enrolled from seven countries (Botswana, Kenya, Rwanda, South Africa, Tanzania, Uganda and Zambia). Of the 3,381 infected index cases, 2,284 (68\%) were female and 1,097 (32\%) were male. The median CD4 count of index patients was 462 cells $/ \mu \mathrm{L}$, the median plasma viral load was $4.1 \log _{10}$ copies $/ \mathrm{mL}$, and $34 \%$ of infected male partners and $55 \%$ of uninfected male partners were circumcised. One hundred three genetically linked new infections were identified in partners; one was in the partner of a treated index case. The incidence in partners of untreated index cases was 2.24 (1.84-2.72) per 100 person-years as compared to 0.37 (95\% CI $0.09-2.04)$ per 100 person-years in partners of treated index cases (adjusted incidence rate ratio 0.08, 95\% CI 0.00-0.57). This population was previously analysed in another abstract (Donnell 2009). 
Lu 2010: Lu and colleagues analysed data from a prospective cohort study that enrolled 1927 heterosexual couples between January 2006 and December 2008 for testing and treatment at county hospitals in China. Serodiscordant couples were identified through an HIV database and enrolled at local hospitals and health centres. The couples received HIV testing every 6 months and in the event of transmission to an uninfected partner, a recent history of sexual behaviours was taken from the participants. Of the 1927 couples, there were 1092 (57\%) HIV-infected male partners and 835 (43\%) HIV-infected female partners. The last recorded CD4 count was $<200$ cells $/ \mu \mathrm{L}$ for 422 index spouses (23\%), and $\geq 350$ cells $\mu$ for 675 (35\%) index partners. Approximately $80 \%$ of the studied couples were treated with antiretroviral therapy. Eightyfour $(4 \%)$ partners seroconverted by the end of follow up, yielding an overall rate of 1.71 per 100 person-years. There was no relationship between the rate of seroconversion and last CD4 count in the index spouse. There was also no effect of ART on preventing HIV transmission in this study as $4.8 \%$ of treated couples and $3.2 \%$ of untreated couples seroconverted (yielding a non-significant rate ratio of $1.44 ; 95 \%$ CI $0.85-2.44$ ).

Cohen 2011: This was a Phase III, two-arm, multicentre RCT that enrolled 1750 serodiscordant heterosexual and male homosexual couples. All index cases had 350-550 CD 4 cells $/ \mu \mathrm{L}$ at baseline and were randomly assigned to immediate ART treatment initiation or delayed treatment until two consecutive measurements of 200$250 \mathrm{CD} 4$ cells/ $\mu \mathrm{L}$ or an AIDS defining illness (HPTN 2011). No participants had histories of injection drug use. All serodiscordant couples were given prevention and adherence counseling and provided with free condoms. In the immediate treatment arm over 1585 person years, there was one HIV transmission to partner that was linked by virological genomic analysis to that of the index case. In the delayed treatment arm over 1567 person years, there were 27 linked HIV transmissions, yielding a rate ratio of $0.04(95 \%$ CI 0.00-0.27). When considering all HIV infections, regardless of confirmatory linkages, there were $35 \mathrm{HIV}$ transmissions in the delayed arm and 4 transmissions in the immediate arm (rate ratio 0.11; 95\% CI 0.04-0.32). Subsequent analyses identified 38 cases, from which 29 (76.3\%) were definitively linked using a phylogenetic analysis of HIV pol sequences, and in 7 cases (18.4\%) the index partner was ruled out as a likely source of HIV infection (Eshleman 2011)

Reynolds 2011: Reynolds and colleagues reported data from a cohort of $250 \mathrm{HIV}$-discordant couples from Rakai, Uganda. They observed 42 seroconversions over 459 person-years of exposure to index patients not on ART (incidence 9.2 per 100 person-years, 95\% CI 6.6-12.4) and none over 53.6 person-years on ART (rate ratio=0.10; 95\% CI 0.01-1.64).

Birungi 2012: Birungi and colleagues examined the effectiveness of ART as prevention in a programmatic setting in rural Uganda without access to viral load testing. The authors enrolled 550 serodiscordant couples and began HAART in 260 couples (CD4 $<=250$ or WHO stage IV illness) and delayed treatment in 290 couples not yet eligible for ART. All couples were tested every 3 months. Ultimately, 586 couples were enrolled with 348 couples (59\%) of the positive participants received ART during the study (249 on ART at enrolment; 99 began ART after enrolment). Median ART-use at enrolment was 2.5 years among couples treated with ART. Median follow up was 1.3 years for all couples. There were 17 infections diagnosed during the follow-up ( 9 infections in the ART group and 8 infections in the non-ART group). Incidence was estimated as 2.09 infections per 100 person years for the ART group and 2.30 infections per 100 person years for the non-ART group. The overall incidence rate ratio was $0.91(95 \%$ CI 0.38-2.20)

Jia 2012: This was a large, national-level study assessing the effect of antiretroviral therapy on HIV transmission risk among discordant couples across China from January 2003 to December 2011. All HIV-infected individuals in China who reported having a spouse or regular sex partner were followed by the Chinese Centre for Disease Control and Prevention (China CDC). Every 6 months HIV-negative partners were tested and HIV-infected partners received repeat CD4 cell count tests. A total of 24,057 discordant couples were identified for the ART-treated cohort and 14,805 discordant couples were identified for the ART-naive cohort and followed over 101,295.1 person-years. Over all couples, a total of $1631 \mathrm{HIV}$ transmissions occurred for an overall rate of 1.6 transmission per 100 person-years (95\% CI 1.5-1.7). Among treated couples, the rate was 1.3 per 100 person years (95\% CI 1.2-1.3) and among the untreated couples the transmission rate was 2.6 per 100 person years (95\% CI 2.4-2.8), yielding an unadjusted $\mathrm{HR}=$ 0.61 (95\% CI 0.55-0.67). After adjusting for duration of followup, sociodemographic variables, route of HIV infection, and baseline $\mathrm{CD} 4$ among index cases, the authors estimated a $\mathrm{HR}=0.74$ (95\% CI 0.65-0.84). Considering couples treated with baseline CD4 < 250 compared to couples untreated the unadjusted $\mathrm{HR}=$ 0.57 (95\% CI 0.45-0.72). Similarly, considering couples treated with baseline CD4 250-349 compared to couples untreated the unadjusted $\mathrm{HR}=0.66$ (95\% CI 0.47-0.94). Lastly, comparing couples treated with baseline CD4 350 or greater with untreated couples, $\mathrm{HR}=0.45$ (95\% CI 0.31-0.66).

\section{Excluded studies}

We excluded data from 13 couples transmission studies in which ART was not given (Operskalski 1997, Ragni 1998, Quinn 2000, Fideli 2001, Gray 2001, Tovanabutra 2002 ,Brill 2003, Mehendale 2004, Wawer 2005, Kayitenkore 2006, Peterson 2007, Peters 2008, Baeten 2010) and 3 couples transmission studies in which all index cases received ART (Barreiro 2006, Bunnell 2006, Bunnell 2008). See Excluded studies for details.

\section{Risk of bias in included studies}

In addition to Cochrane Collaboration's tool for assessing the risk of bias for each individual study (Higgins 2008), we applied the 
Newcastle-Ottawa Scale for bias assessment within observational studies to all included observational studies (Newcastle-Ottawa). The risk of bias for the included observational studies was assessed on the data and outcomes published within the manuscripts. Please see Figure 2 and Appendix 3 for assessment results from the Newcastle-Ottawa Scale and Cochrane risk of bias assessments. All observational studies had cohorts that were representative of treated and untreated, serodiscordant couples. Only three out of the nine included observational studies that estimated the effect of ART after adjusting for either age, sex, or frequency of sex among serodiscordant couples. Three of nine observational studies explicitly described complete follow up of the study participants and/or described the characteristics of the participants lost to follow up.

\section{Allocation}

In the trial randomisation was stratified by site using permuted block randomisation to achieve approximately 1:1 allocation to each treatment group within each site.

\section{Blinding}

The trial was unblinded.

\section{Incomplete outcome data}

There was no evidence of incomplete outcome data from the trial. Three of nine included observational studies discussed either complete follow up of subjects or characteristics of those lost to follow up.

\section{Selective reporting}

None detected.

\section{Other potential sources of bias}

None detected.

\section{Effects of interventions}

See: Summary of findings for the main comparison Antiretroviral Therapy for HIV Prevention in Serodiscordant Couples (Part A); Summary of findings 2 Antiretroviral Therapy for HIV Prevention in Serodiscordant Couples (Part B)

The single RCT comparing immediately treated serodiscordant couples and delayed treatment couples showed that ART was associated with a significantly decreased risk of HIV transmission (RR 0.04, 95\% CI 0.00-0.27).

In eight of the nine cohort studies we analysed, ART was associated with a decreased risk of transmission from infected index cases to uninfected partners, ranging from rate ratios of 0.08 to 0.91 . The only cohort study that we identified that did not find this decreased, unadjusted risk was Lu 2010, which did not provide person time data needed to calculate a rate ratio. Using the median person time for both treated and untreated groups in Lu 2010, the RR comparing treated couples with untreated couples was 1.44 (95\% CI 0.85-2.44).

Meta-analysis

As there was only a single RCT, we did not combine its results with those of the observational studies. The RR of phylogenetically linked HIV transmissions (where the newly infected partner had a genetically identical strain as the originally infected partner) in this trial was 0.04 (95\% CI 0.00-0.27) (Cohen 2011), yielding a number needed to treat (NNT) of 60. Considering all HIV transmissions to partners (virologically linked and not virologically linked), the RR was 0.11 (95\% CI 0.04-0.32). See Figure 5 and Figure 6.

Figure 5. Forest plot of comparison: I Delayed vs Immediate ART (RCTs), outcome: I.I Linked Incident HIV Infection.

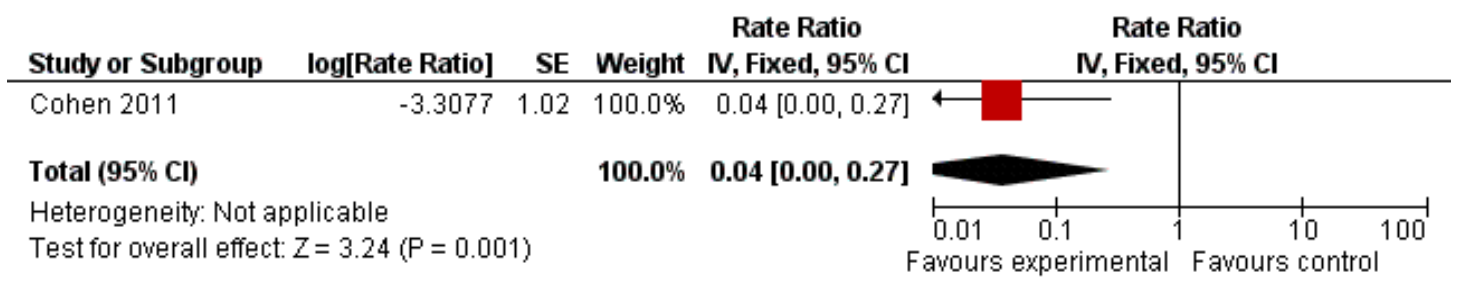

Antiretroviral therapy for prevention of HIV transmission in HIV-discordant couples (Review) 
Figure 6. Forest plot of comparison: I Delayed vs Immediate ART (RCTs), outcome: I.2 All Incident HIV Infection.

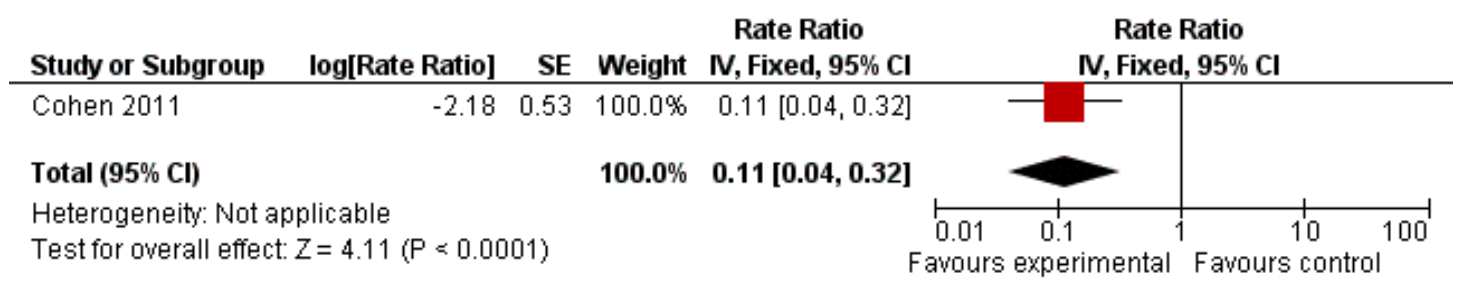

We performed a meta-analysis of the nine identified observational studies to estimate the effect of ART on HIV incidence reduction for partners of infected spouses. The summary rate ratio for all nine studies was 0.58 [95\% CI $0.35,0.96$ ], with substantial heterogeneity $\left(\mathrm{I}^{2}=64 \%\right)$ (see Figure 7 ). The ten studies ( 9 observational studies and 1 RCT) identified 2112 episodes of HIV transmission, 1016 among treated couples and 1096 among untreated couples. To explore the potential influence of the study without adequate person time data (Lu 2010) or monotherapy (Musicco
1994), we performed a sensitivity analysis removing the results of these studies. The meta-analysis of the remaining seven studies yielded a rate ratio of 0.36 [95\% CI $0.17,0.75]$ with substantial heterogeneity $\left(\mathrm{I}^{2}=62 \%\right)$ (see Figure 8 ). Furthermore, we analysed the remaining seven studies with a fixed-effects model to see if there was any consistency between the two approaches. The fixedeffects model yielded a higher rate ratio and narrower confidence interval $[\mathrm{RR}=0.71 ; 95 \%$ CI 0.63-0.81].

Figure 7. Forest plot of comparison: 2 Treated with ART vs Not Treated with ART (Observational Studies), outcome: 2.I Incident HIV Infection.

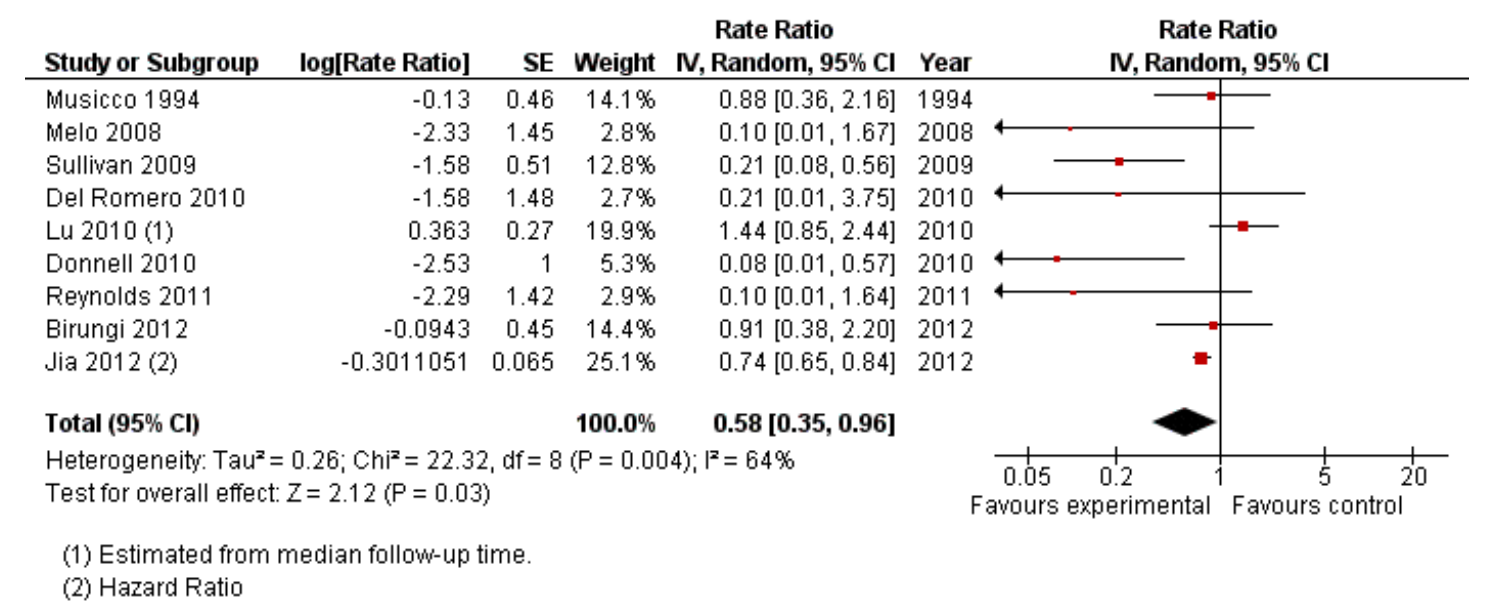


Figure 8. Forest plot of comparison: 3 Treated with ART vs Not Treated with ART (Observational Studies, sensitivity analysis), outcome: 3.I Incident HIV Infection.

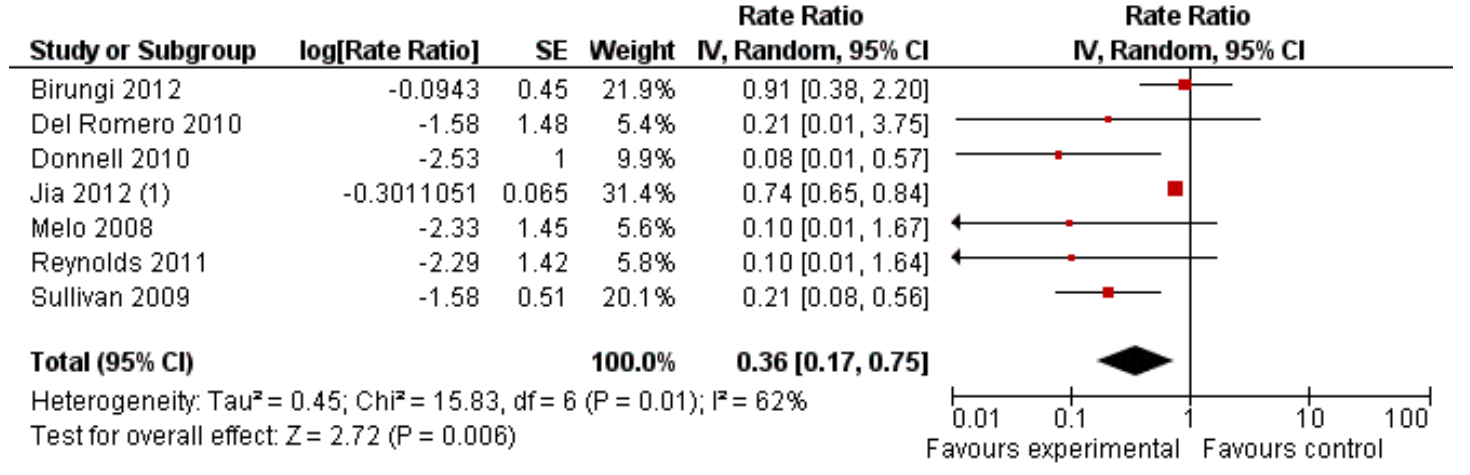

(1) Hazard Ratio

We also performed subgroup analyses to see if the effect of ART on prevention of HIV differed by the level of CD4 in the index partner (see Figure 9). Specifically, we categorised CD4 into three groups-- $<200$ cells $/ \mu, 200-349$ cells $/ \mu \mathrm{L}$, and $\geq 350$ cells $/ \mu L$. Five studies had data available for subjects whose CD4 was less than 200 cells/ $\mu$ L (Melo 2008, Del Romero 2010, Donnell 2010, Reynolds 2011, Jia 2012), four studies had data for subjects whose CD4 was 200-349 cells/ $\mu$ L (Melo 2008, Del Romero 2010, Donnell 2010, Jia 2012), and four studies had data for subjects whose CD4 was $\geq 350$ cells $/ \mu$ (Del Romero 2010, Donnell 2010, Cohen 2011, Jia 2012). The subgroup analysis of studies with patients with $<200$ cells $/ \mu \mathrm{L}$ yielded a rate ratio of 0.12 [95\% CI $0.02,0.81]$ with substantial heterogeneity $\left(\mathrm{I}^{2}=71 \%\right)$. The subgroup analysis of studies with patients with $200-349$ cells $/ \mu \mathrm{L}$ yielded a rate ratio of 0.66 [95\% CI $0.47,0.92]$ with no heterogeneity $\left(\mathrm{I}^{2}=0 \%\right)$. All patients in the RCT had $\geq 350 \mathrm{CD} 4$ cells $/ \mu \mathrm{L}$ at assignment. As noted above, that study found a rate ratio of 0.04 (95\% CI 0.00 $0.27)$. In the three observational studies, we estimated a rate ratio of 0.12 [95\% CI $0.01,1.99$ ] from the subgroup analysis of observational studies with patients with $\geq 350$ cells/ $\mu \mathrm{L}$. Excluding the RCT, in this subgroup the total number of HIV transmissions was 277 , with 247 cases among untreated couples. In the observational studies, tests for interaction between the CD4 subgroups were performed and yielded no statistically significant difference between groups. Specifically, the test for interaction between the $<200$ cells $/ \mu \mathrm{L}$ group and the group with $200-349$ cells/ $\mu \mathrm{L}$ yielded an RRR of 0.18 (95\% CI 0.03-1.19). Further, when comparing the $<200$ cells/ $\mu \mathrm{L}$ group with the $\geq 350$ cells/ $\mu$ group, the test for interaction yielded an RRR of 1.00 (95\% CI 0.04-25.27). Finally, a test for interaction between the group with $200-349$ cells $/ \mu \mathrm{L}$ and the $\geq 350$ cells/ $\mu$ group yielded an RRR of 5.50 (95\% CI 0.38 79.25). 
Figure 9. Forest plot of comparison: 3 Treated with ART vs Not Treated with ART $(<200,200-350$, and $\rangle$ 350 CD4 Subgroup Analysis) (Observational Studies), outcome: 3.I Incident HIV Infection.

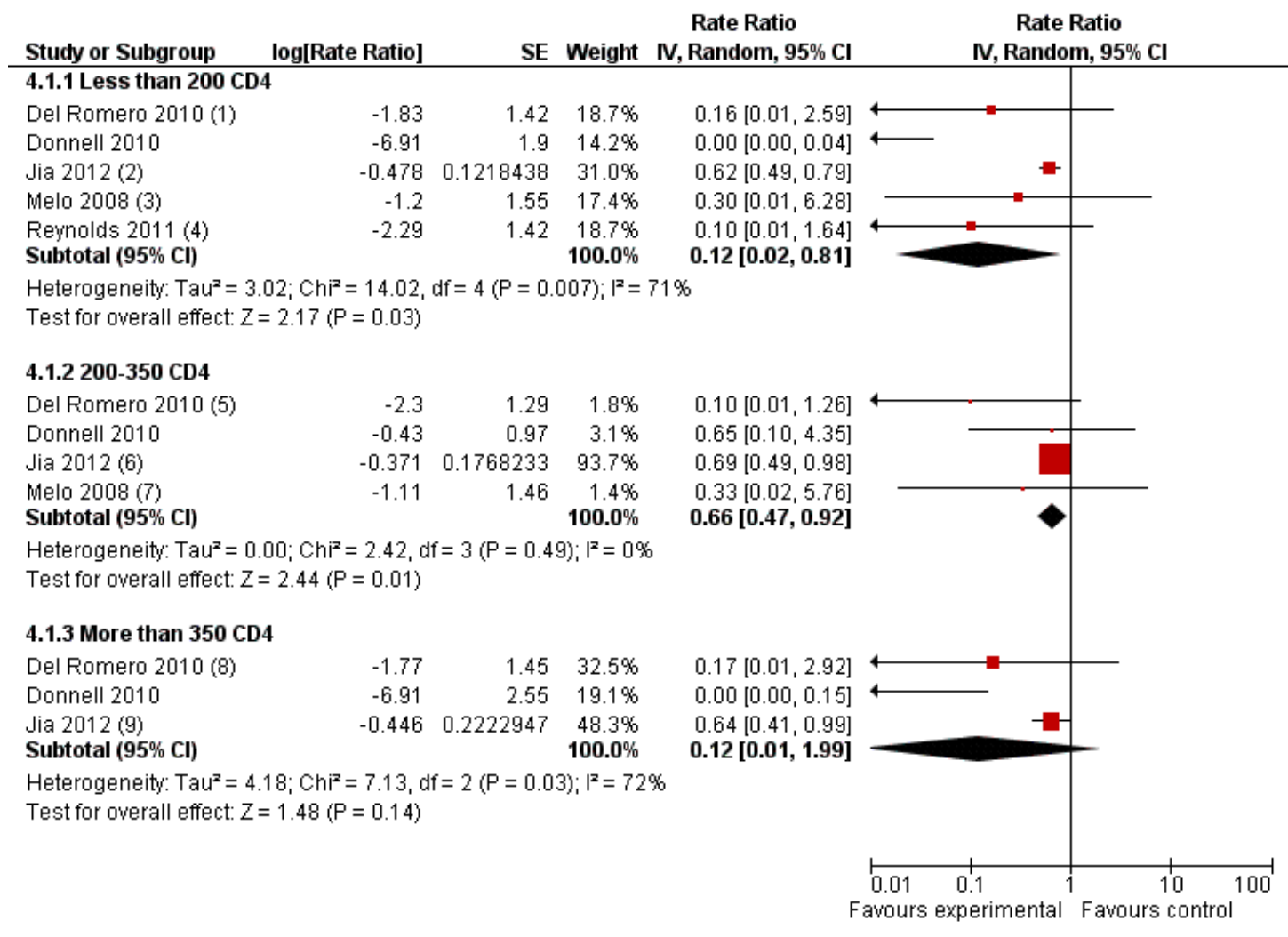

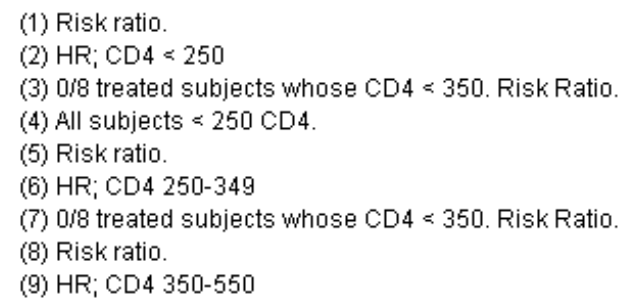

Additionally, we performed a subgroup analysis of the effect of ART on HIV prevention by the gender of the index case (see Figure 10). Only three observational studies provided enough data to analyse this subgroup (Del Romero 2010, Jia 2012, and Sullivan 2009). A summary estimate of the effect of ART on incident HIV among female index cases showed a non-significant trend toward a reduction of risk when compared to untreated female index cases (relative risk=0.39; 95\% 0.13-1.18). Similarly, if a treated man was the index case, the risk of transmission was not significantly lower when compared to untreated index male cases (relative risk $=0.11$; 95\% CI 0.01-1.62). Tests for interaction showed no statistically significant difference between index case subgroups ( $R R R=3.55$, 95\% CI 0.22-56.73).

Antiretroviral therapy for prevention of HIV transmission in HIV-discordant couples (Review) 
Figure 10. Forest plot of comparison: 5 Treated with ART vs Not Treated with ART (Female/Male Subgroup Analysis) (Observational Studies), outcome: 5.I Incident HIV Infection.

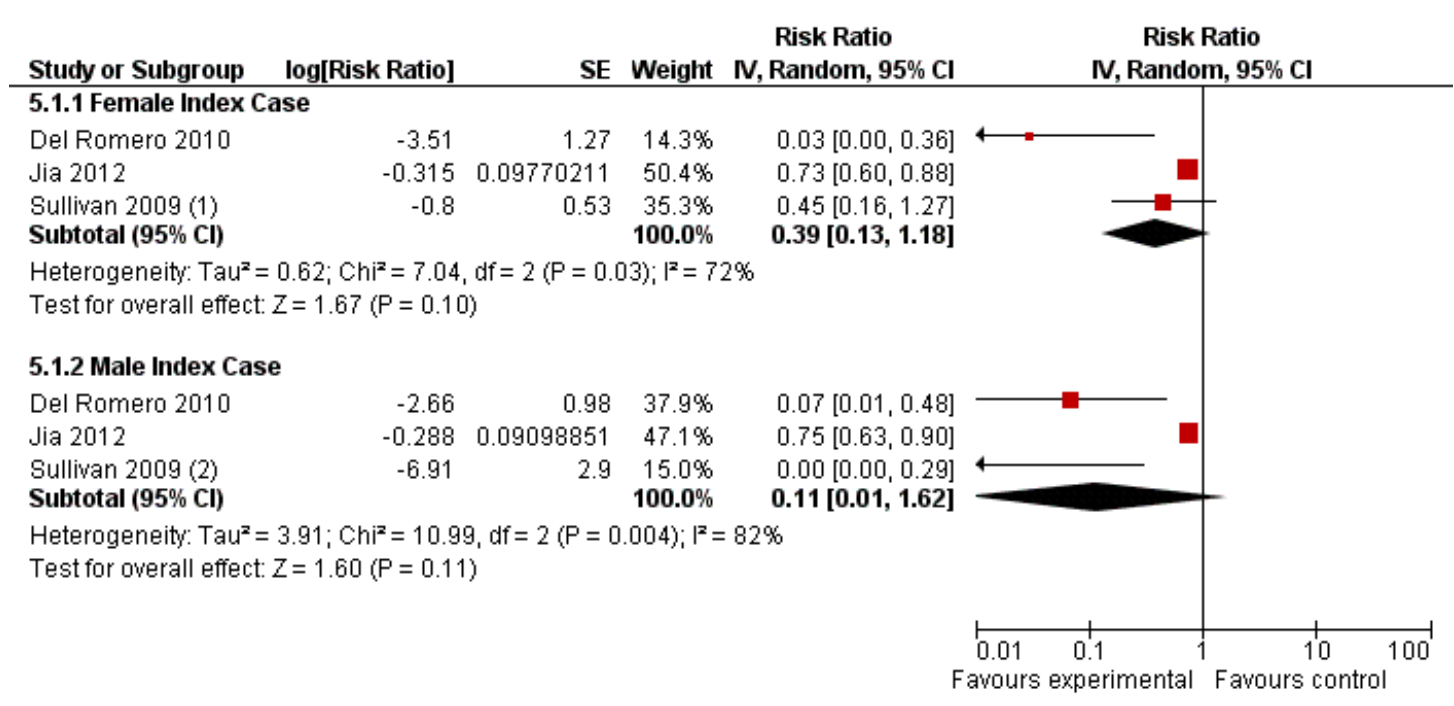

(1) Estimate is a rate ratio.

(2) Estimate is a rate ratio.

We also performed a subgroup analysis within the nine observational studies of the effect of ART on HIV prevention by income level of the country (see Figure 11). Specifically, the effect of ART on HIV prevention in low- and middle-income countries was estimated as $\mathrm{RR}=0.53$ [95\% CI $0.29,0.97$ ] with significant heterogeneity $\left(\mathrm{I}^{2}=72 \%\right)$. The effect of ART on HIV prevention in high-income countries was estimated as $\mathrm{RR}=0.77$ [95\% CI 0.33, $1.83]$ with low heterogeneity $\left(I^{2}=0 \%\right)$. Again, tests for interaction yielded no statistically significant difference between subgroups of income level (RRR=0.69, 95\% CI 0.24-1.96).

Antiretroviral therapy for prevention of HIV transmission in HIV-discordant couples (Review) 
Figure I I. Forest plot of comparison: 5 Treated with ART vs Not Treated with ART (Subgroup Analysis: LMIC) (Observational Studies), outcome: 5.I Incident HIV Infection.

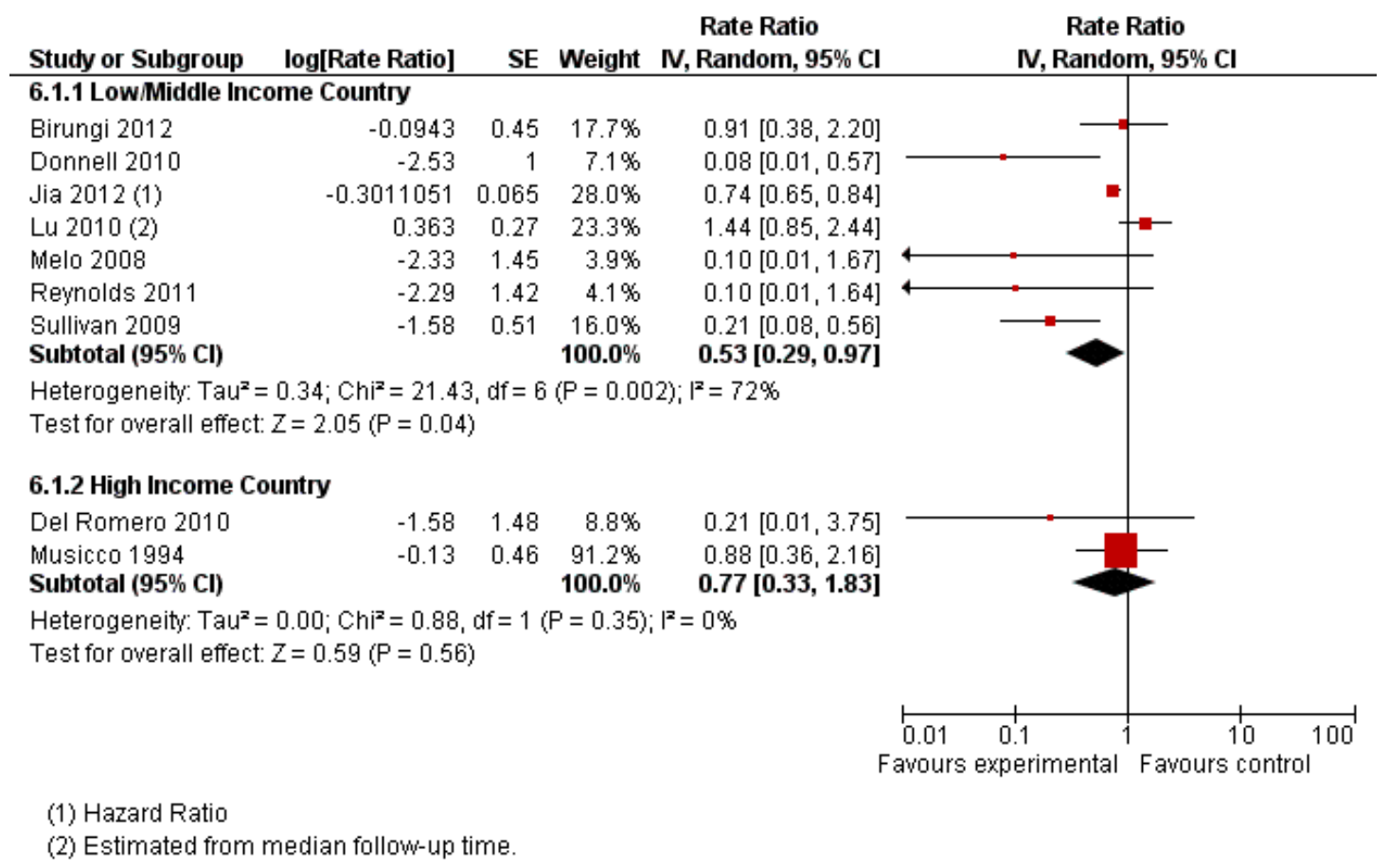

Severe adverse events (SAEs) have been reported from the RCT. SAEs were not frequently reported in the observational studies. Cohen 2011 report that $14 \%$ of participants in both the delayed treatment arm and the early treatment arm had one or more severe or life-threatening events (Grade 3 or 4 ), suggesting no increased risk between study arms $(\mathrm{RR}=1.06$; 95\% CI 0.84-1.33) (see Figure 12). The most frequent SAEs were infections, gastrointestinal disorders, metabolic and nutritional disorders and psychiatric and nervous system disorders. In contrast, Grade 3 or 4 laboratory abnormalities, which most often included neu- tropenia, abnormal phosphate levels and total bilirubin elevations, were more likely found among participants receiving therapy early (27\%) when compared to participants receiving delayed treatment $(18 \%)(\mathrm{RR}=1.49 ; 95 \%$ CI 1.25-1.77) (see Figure 13). Among the observational studies, Del Romero 2010 reported that genitourinary infections occurred in 8/144 treated couples (6\%) and 62/ 388 among untreated couples (16\%) during follow up. Lu 2010 reported that 266 (19\%) of 1369 treated couples switched ARTs. Nearly all couples who switched $(n=259 ; 97 \%)$ did so as a result of adverse events, while three other patients developed resistance.

Figure 12. Forest plot of comparison: I Delayed vs Immediate ART (RCTs), outcome: I.3 Severe or LifeThreatening Adverse Events (Grade 3 or 4).

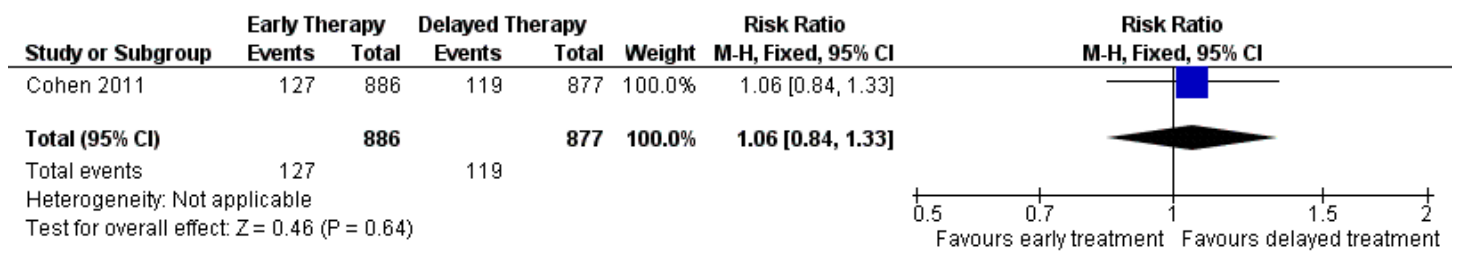


Figure 13. Forest plot of comparison: I Delayed vs Immediate ART (RCTs), outcome: I.4 Grade 3 or 4 Laboratory Abnormalities.

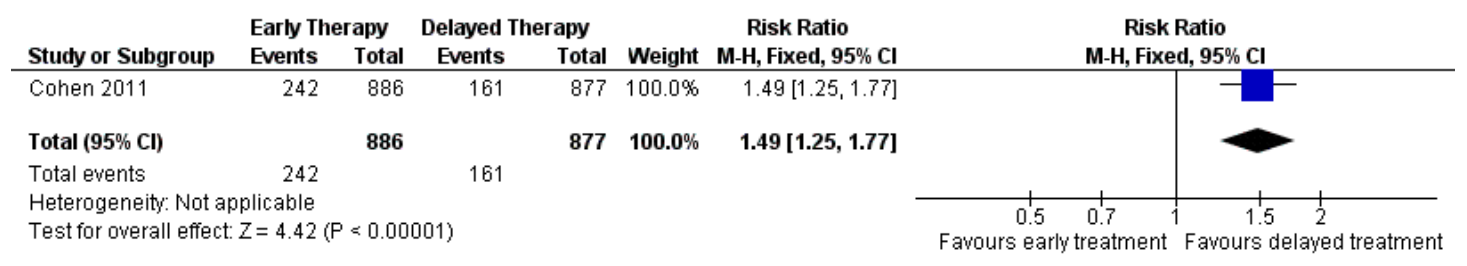


ADDITIONAL SUMMARY OF FINDINGS [Explanation]

Antiretroviral Therapy for HIV Prevention in Serodiscordant Couples (Part B)

Patient or population: Serodiscordant couples

Settings: Botswana, Brazil, China, Italy, Kenya, Rwanda, South Africa, Spain, Tanzania, Uganda, and Zambia

Intervention: Antiretroviral Therapy

\begin{tabular}{|c|c|c|c|c|c|c|}
\hline \multirow[t]{3}{*}{ Outcomes } & \multicolumn{2}{|c|}{ Illustrative comparative risks* $(95 \% \mathrm{Cl})$} & \multirow{3}{*}{$\begin{array}{l}\text { Relative effect } \\
(95 \% \mathrm{Cl})\end{array}$} & \multirow{3}{*}{$\begin{array}{l}\text { No of participants } \\
\text { (studies) }\end{array}$} & \multirow{3}{*}{$\begin{array}{l}\text { Quality of the evidence } \\
\text { (GRADE) }\end{array}$} & \multirow[t]{3}{*}{ Comments } \\
\hline & Assumed risk & Corresponding risk & & & & \\
\hline & Control & Antiretroviral therapy & & & & \\
\hline $\begin{array}{l}\text { HIV incidence: gen- } \\
\text { der subgroup (female } \\
\text { cases) }\end{array}$ & 74 per $1000^{1,2}$ & $\begin{array}{l}29 \text { per } 1000 \\
(10 \text { to } 88)^{2}\end{array}$ & $\begin{array}{l}\mathbf{R R} \mathbf{0 . 3 9} \\
(0.13 \text { to } 1.18)\end{array}$ & $\begin{array}{l}15608 \\
\text { (3 studies) }\end{array}$ & $\begin{array}{l}\oplus \oplus \bigcirc \bigcirc \\
\text { low }^{3,4}\end{array}$ & $\begin{array}{l}\text { Observational } \\
\text { only }\end{array}$ \\
\hline $\begin{array}{l}\text { HIV incidence: gender } \\
\text { subgroup (male Cases) }\end{array}$ & 48 per $1000^{1,2}$ & $\begin{array}{l}5 \text { per } \mathbf{1 0 0 0} \\
(0 \text { to } 78)^{1,2}\end{array}$ & $\begin{array}{l}\text { RR } 0.11 \\
\text { (0.01 to 1.62) }\end{array}$ & $\begin{array}{l}25073 \\
\text { (3 studies) }\end{array}$ & $\begin{array}{l}\oplus \oplus \circ \bigcirc \\
\text { low }^{3,4}\end{array}$ & $\begin{array}{l}\text { Observational } \\
\text { only }\end{array}$ \\
\hline $\begin{array}{l}\text { HIV incidence: low-/mid- } \\
\text { dle-income countries }\end{array}$ & 54 per $1000^{1,2}$ & $\begin{array}{l}29 \text { per } 1000 \\
(16 \text { to } 53)^{1,2}\end{array}$ & $\begin{array}{l}\text { RR } \mathbf{0 . 5 3} \\
\text { (0.29 to } 0.97 \text { ) }\end{array}$ & $\begin{array}{l}45029 \\
\text { (7 studies) }\end{array}$ & $\begin{array}{l}\oplus \oplus \circ \bigcirc \\
\text { low3,5 }\end{array}$ & $\begin{array}{l}\text { Observational } \\
\text { only }\end{array}$ \\
\hline $\begin{array}{l}\text { HIV incidence: high in- } \\
\text { come countries }\end{array}$ & 31 per $1000^{1,2}$ & $\begin{array}{l}24 \text { per } 1000 \\
(10 \text { to } 57)^{1,2}\end{array}$ & $\begin{array}{l}\text { RR } \mathbf{0 . 7 7} \\
(0.33 \text { to } 1.83)\end{array}$ & $\begin{array}{l}1061 \\
\text { (2 studies) }\end{array}$ & $\begin{array}{l}\oplus \bigcirc \bigcirc \bigcirc \\
\text { very low }\end{array}$ & $\begin{array}{l}\text { Observational } \\
\text { only }\end{array}$ \\
\hline
\end{tabular}

*The basis for the assumed risk (e.g. the median control group risk across studies) is provided in footnotes. The corresponding risk (and its $95 \%$ confidence interval) is based on the assumed risk in the comparison group and the relative effect of the intervention (and its $95 \% \mathrm{Cl}$ ).

Cl: confidence interval; RR: risk ratio;

GRADE Working Group grades of evidence

High quality: Further research is very unlikely to change our confidence in the estimate of effect.

Moderate quality: Further research is likely to have an important impact on our confidence in the estimate of effect and may change the estimate.

Low quality: Further research is very likely to have an important impact on our confidence in the estimate of effect and is likely to change the estimate. 


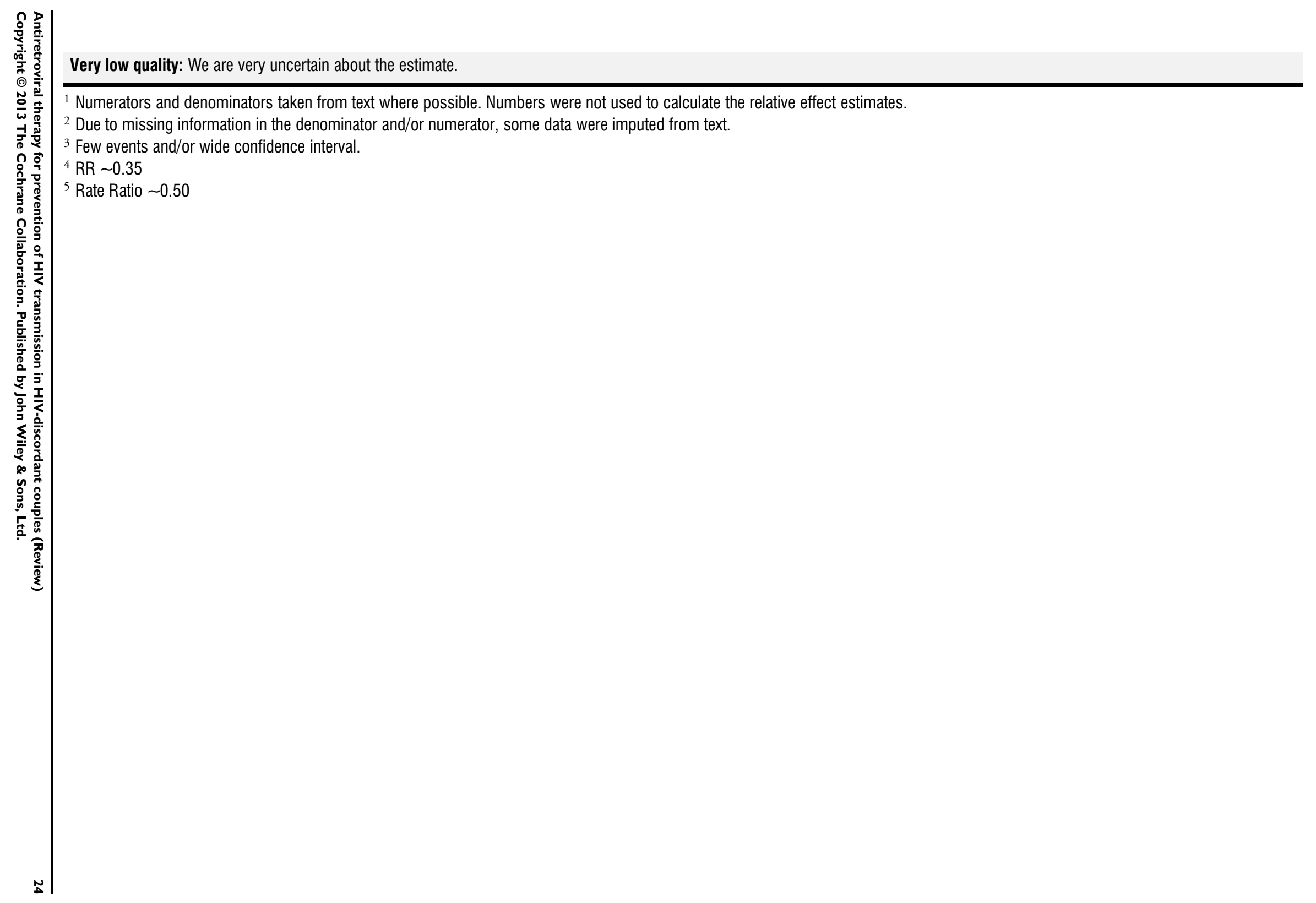




\section{I SCUSSIO N}

\section{Summary of main results}

We found that ART was associated with decreased risk of transmission of HIV in discordant couples. This intervention effect was particularly pronounced in the one large multicentre RCT that has been completed but also appeared in several observational studies that had adjusted for a variety of cofactors for transmission. Interestingly, the largely historical analyses of Musicco 1994 and Del Romero 2010 of patients on monotherapy and dual therapy even found pronounced independent protective effects for ART. More recent observational studies, such as Sullivan 2009, Donnell 2010, and Reynolds 2011, have found even larger effects than these earlier studies, suggesting that more potent ART regimens are associated with even greater reductions in transmission, though Jia 2012 and Birungi 2012 found less pronounced reductions in transmission. Only one observational study found an increased risk, albeit statistically non-significant, of HIV transmission among ART treated couples compared to untreated couples ( $\mathrm{Lu} 2010$ ). The authors' study objective was not to examine the effect of ART in serodiscordant couples but rather to estimate HIV incidence and clinical progression, quality of life and behavioural risk factors. Unpublished data suggest that the treated couples were followed for nearly three times longer than untreated couples (3532 years and 1385 years, respectively), thus, possibly allowing for more opportunity for infection among the treated couples. Nevertheless, it should be noted that the authors found no difference in rates of HIV transmission between ART-treated couples (4.8\%) and untreated couples $(3.2 \%)$. A later analysis, also from China (Jia 2012), did find a statistically significant decreased risk of transmission in treated couples compared to untreated couples. It should be noted that Jia 2012 reported on all serodiscordant couples in China who test HIV-positive at the National Center for AIDS/ STD Control and Prevention at the Chinese Center for Disease Control and Prevention from 2003-2011, while Lu 2010 reported on serodiscordant couples reporting to a local subsidiary office of the National Center for AIDS/STD Control and Prevention from 2006-2008. As such, it is likely that Jia 2012 has re-analyzed some of the same serodiscordant couples as Lu 2010, another possibility we considered when performing the sensitivity analysis by removing Lu 2010 data from our overall effect.

We explored the effect of ART on transmission risk of HIV in discordant couples in CD4 subgroup analyses to see if the effect differed by CD 4 stratum. Unfortunately, most observational studies did not report risk of HIV transmission stratified by the index case's baseline CD4. Data from HPTN 052 clearly demonstrate the large and positive benefit among index partners with between 350 and 550 CD4 cells/ $\mu \mathrm{L}$ (Grinsztejn 2011).

It is important to note that participants in this study were longterm couples, and, as such, they do not represent all situations in which transmission risk exists. Transmission during the acute phase of HIV infection is an important contributor to overall incidence (Miller 2010) and would not be averted by the couples counseling and partner therapy discussed in this review.

Several relevant studies are in progress. Please see Appendix 4.

\section{Overall completeness and applicability of evidence}

HPTN 052 provides clear and compelling evidence of benefit for treating index participants with between 350 and 550 CD4 cells/ $\mu \mathrm{L}$. Other data we examined that bear on the benefit of therapy are from partnerships where the index participants had <350 CD4 cells $/ \mu \mathrm{L}$, and unmeasured confounding remains a significant issue in these cohort studies. Given that we did not conduct an individual patient database meta-analysis for the observational studies, we were unable to control for a variety of cofactors, such as number of exposures, circumcision, HIV viral load, sexually transmitted infections, condom use or potency of ART. Nonetheless, the strength and consistency of the evidence and the evidence contributed by the large, high-quality RCT argue strongly in favour of a potent biological effect of ART on reducing risk of HIV transmission in discordant couples.

We found no studies that explored outcomes such as the acquisition of primary drug resistant HIV by previously uninfected partners, HIV-related mortality, HIV-related morbidity and quality of life, although subsequent publications from the HPTN 052 trial will likely shed light on these outcomes. Because the vast majority of the couples in the included studies were heterosexual, the findings of this review may not be generalisable to populations of men who have sex with men. Other concerns that must be addressed are the additional financial costs of recommending ART for prevention, which would make implementation difficult if not impossible in many resource-constrained settings. There is also the potential for significant implementation and adherence challenges if ART is offered earlier to discordant couples (e.g., expanding treatment indications) when large numbers of patients that meet clinical or immunologic criteria for treatment are remain untreated.

\section{Quality of the evidence}

\section{GRADE}

In the GRADE system, well-conducted RCTs (without additional limitations) provide high quality evidence, and observational studies without any special strengths (and without additional limitations) provide low-quality evidence. The quality of evidence provided by a body of literature comprised exclusively of observational studies would thus be graded as "low." In this analysis, we found that the quality of evidence was high, based on the large effect size found in the RCT, the biological plausibility of the relationship and the strength, temporality and the consistency of this relationship in the supporting observational studies. Please see Summary of findings for the main comparison and Summary of findings 2 for details. 


\section{Potential biases in the review process}

Biases in the review process were minimised by not limiting the search by language, by performing a comprehensive search of databases and conference proceedings and by contacting experts in the field for unpublished and ongoing studies. We explored publication bias for the observational studies by using funnel plots (see Figure 14 and Figure 15). Based on only nine studies, it is difficult to adequately assess publication bias. However, Figure 14 may suggest publication bias, but the assymetry in the plot could also be an artefact of the true effect size differences between high precision studies and low precision studies. Furthermore, RR data were not available for all studies, which in turn could have influenced these estimated effect sizes.

Figure 14. Funnel plot of comparison: I Treated with ART vs Not Treated with ART (Observational Studies), outcome: 2.I Incident HIV Infection.

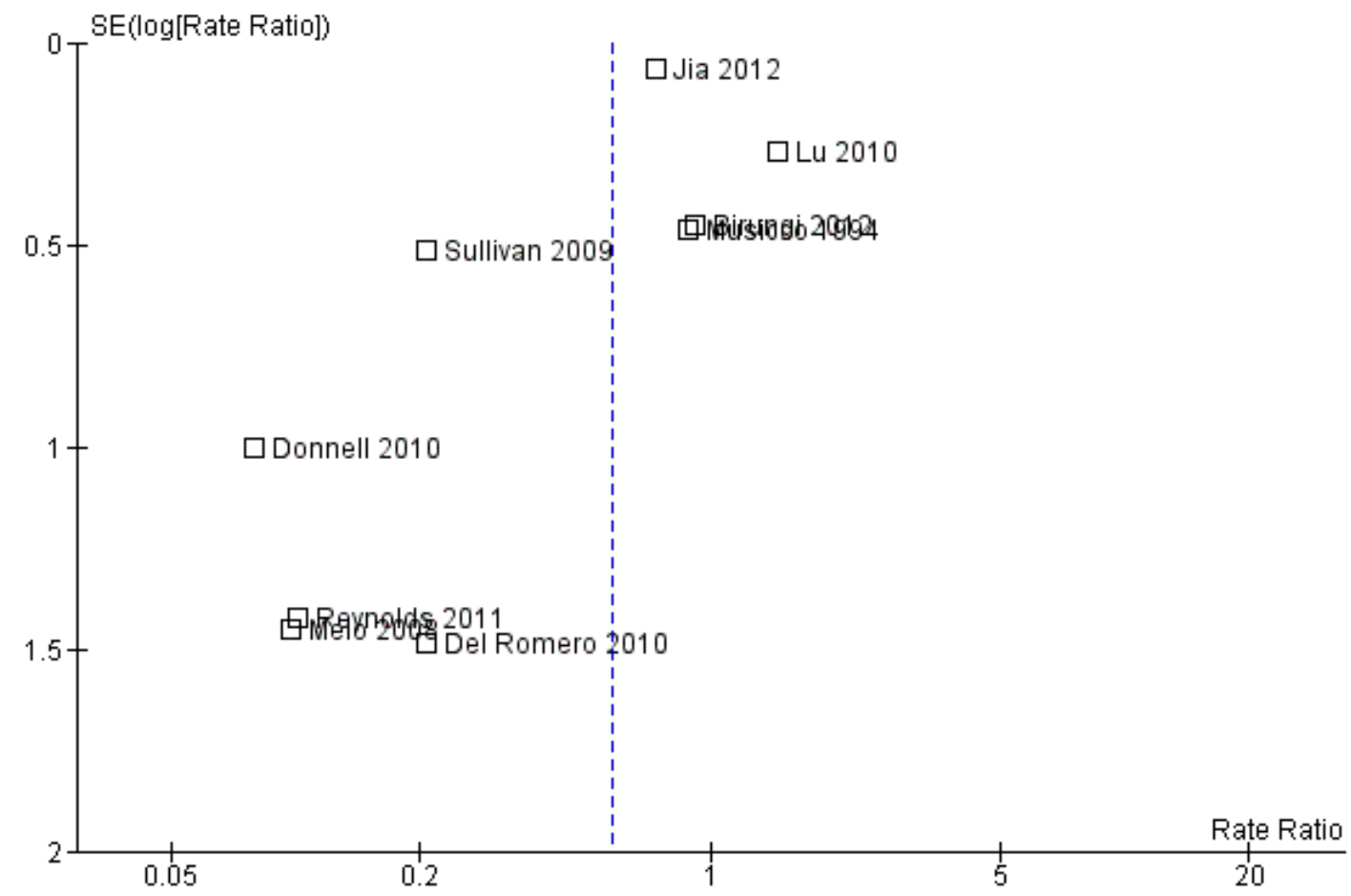


Figure 15. Funnel plot of comparison: 2 Treated with ART vs Not Treated with ART (Observational Studies, sensitivity analysis), outcome: 3.I Incident HIV Infection.

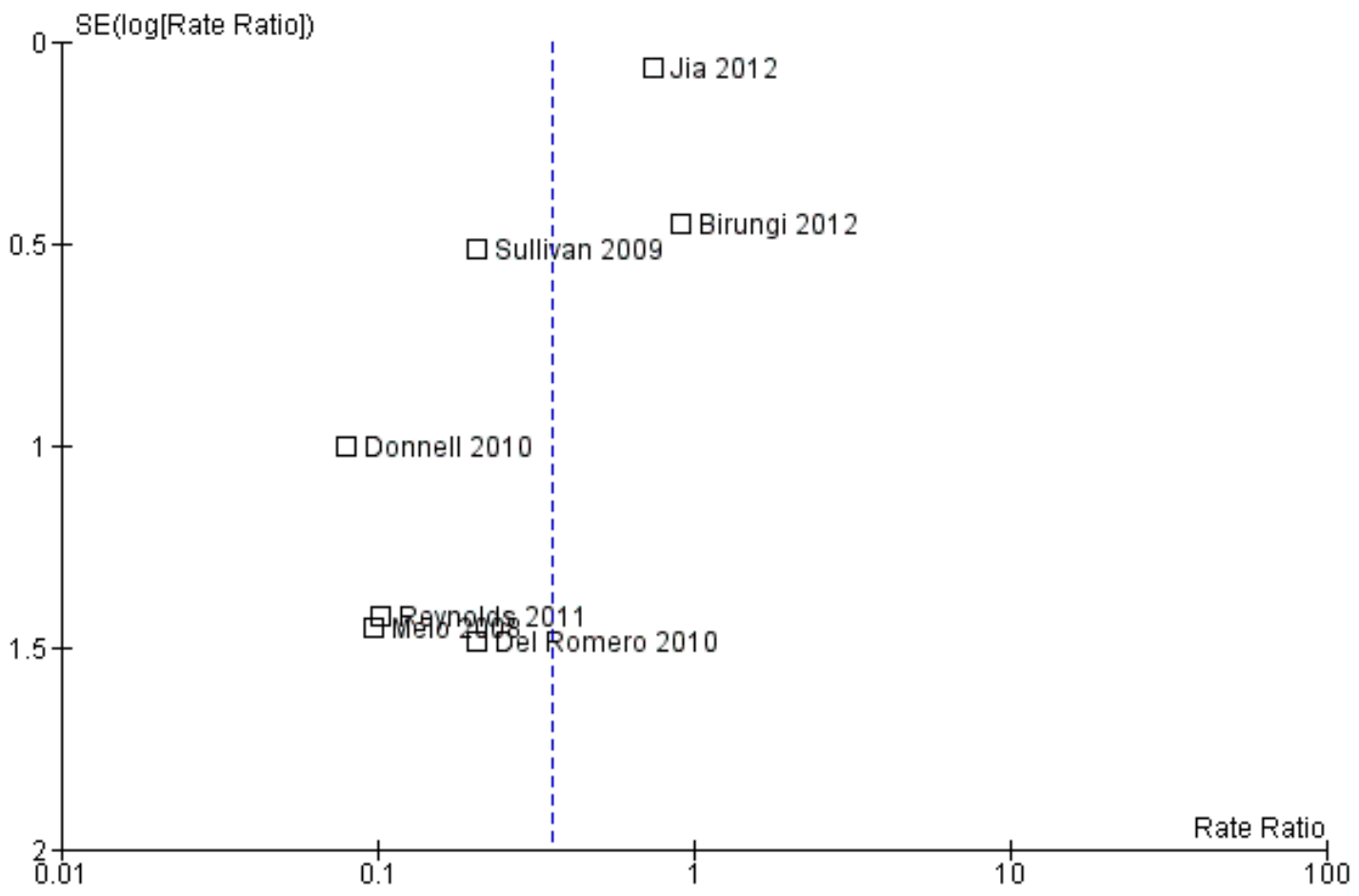

\section{Agreements and disagreements with other studies or reviews}

Our findings are consistent with those of another recent review (Attia 2009).

The review by Attia and colleagues (Attia 2009) was focused differently than ours. The objective of Attia 2009 was to estimate HIV transmission rates among serodiscordant couples with various treatment experience, while our review's objective is to estimate the pooled risk of transmission, comparing ART-treated couples with ART-untreated couples. Attia 2009 includes three types of studies: a) studies of only ART-treated couples, b) studies of only untreated couples, and c) studies of both ART-treated and untreated couples. Our review includes only studies with both ART-treated and untreated couples. Four of the studies identified in our review were also included in Attia 2009: Castilla 2005 (Del Romero 2010), Melo 2008, Reynolds 2011, and Sullivan 2009. No formal assessment of evidence quality was performed in Attia 2009.

\section{AUTHORS' CONCLUSIONS}

\section{Implications for practice}

From the evidence provided by one RCT and nine observational studies, ART has been shown be a potent intervention for prevention of HIV in discordant couples. In 2012 WHO issued guidelines on serodiscordant couples to recommend that the partner living with HIV be offered ART regardless of CD4 count (WHO 2012). Patients in discordant couples beginning ART should be counselled that adherence to ART can also reduce their risk of transmitting HIV to their partners. A policy question remaining to be addressed is how much effort should be focused on treating individuals with $\geq 350 \mathrm{CD} 4$ cells/ $\mu \mathrm{L}$ when access to ART for persons with $<350 \mathrm{CD} 4$ cells $/ \mu \mathrm{L}$ is far from universal. Significant questions remain about durability of protection, cumulative antiretroviral toxicity, when to start treating an infected partner (for instance, at diagnosis or at a specific CD4 or plasma viral load level) and transmission of ART-resistant strains to partners.

The success of this intervention likely relies on good adherence, especially in stable couples. Programmes should be designed that include counselling, support, follow up and mutual disclosure, as these components may have a role in supporting adherence. In addition to ART provision, limitations in resources needed to 
implement such expanded ART indications must be addressed.

\section{Implications for research}

Additional data are needed on durability of protection for uninfected partners, adverse events associated with earlier initiation of ART, including effects of longer-term ART, the potential for earlier development of antiretroviral resistance (resulting in a need to change regimens prematurely) and HIV morbidity, quality of life and the potential for risk compensation. Not only are there are multiple opportunities to examine these issues in existing cohorts, but there are several RCTs underway that will likely help strengthen the observational evidence.

\section{ACKNOWLEDGEMENTS}

We would like to thank Gail Kennedy, Caitlin Kennedy, Jesus Castilla, Jorge del Romero, Karin Nielsen, Breno Santos, Reuben Granich and Ying-Ru Lo for their collaboration and support.

\section{R E F E R E N C E S}

\section{References to studies included in this review}

Birungi 2012 \{published data only (unpublished sought but not used)\} J Birungi, H Wang, M Ngolobe, K Muldoon, S Khanakwa, R King, P Kaleebu, K Shannon, L Lourenco, J Min, J Montaner, E Mills, Y Chen, DM Moore. Lack of Effectiveness of ART as an HIV Prevention Tool for Serodiscordant Couples in a Rural ART Program in Uganda. XIX International AIDS Conference. July 23-27, 2012, Washington DC.

Cohen 2011 \{published data only (unpublished sought but not used)\} * Cohen M, Chen Y, McCauley M, et al.Prevention of HIV-1 infection with early antiretroviral therapy. $\mathrm{N} \mathrm{Engl} \mathrm{J}$ Med 2011; Vol. 10.1056/nejmoa1105243.

Del Romero 2010 \{published data only\} Del Romero J, Castilla J, Hernando V, Rodriguez C, Garcia $\mathrm{S}$. Combined antiretroviral treatment and heterosexual transmission of HIV-1: cross sectional and prospective cohort study.. BMJ 2010;340:c2205.

Donnell 2010 \{published data only\} Donnell D, Baeten J, Kiarie J, Thomas K, Stevens W, Cohen C, McIntyre J, Lingappa J, Celum C. Heterosexual HIV-1 transmission after initiation of antiretroviral therapy: a prospective cohort analysis.. Lancet 2010;6736(10): 2092-2098.

Jia 2012 \{published data only (unpublished sought but not used)\} Jia Z, Ruan Y, Li Q, Xie P, Li P, Wang X, Chen RY, Shao $Y$. Antiretroviral therapy to prevent HIV transmission in serodiscordant couples in China (2003-11): a national observational cohort study. Lancet 2012;pii: S0140-6736 (12)61898-4: [Epub ahead of print].

Lu 2010 \{published data only\}

Lu Wang, Zeng Ge, Jing Luo, Duo Shan, Xing Gao, Guowei Ding, Jian-ping Zhou, Wen-sheng He, Ning Wang. HIV Transmission Risk Among Serodiscordant Couples: A Retrospective Study of Former Plasma Donors in Henan, China.. JAIDS 2010;55:232-238.

Melo 2008 \{published data only\}

Melo MG, Santos BR, Lira RD, Varella IS, Turella ML, Rocha TM, Nielsen-Saines K. Sexual Transmission of HIV-
1 Among serodiscordant couples in Porto Alegre, Southern Brazil. Sex Transm Dis 2008;35:912-915.

Musicco 1994 \{published data only\}

Musicco M, Lazzarin A, Nicolosi A, Gasparini M, Costigliola P, Arici C, Saracco A. Antiretroviral treatment of men infected with human immunodeficiency virus type 1 reduces the incidence of heterosexual transmission. Arch Intern Med 1994;154:1971-1976.

\section{Reynolds 2011 \{published data only\}}

Reynolds S, Makumbi F, Nakigozi G, Kagaayi J, Gray R, Wawer M, Quinn T, Serwadda D. HIV-1 transmission among HIV-1 discordant couples before and after the introduction of antiretroviral therapy.. AIDS 2011;25: 473-477.

\section{Sullivan 2009 \{published data only\}}

Sullivan P, Kayitenkore K, Chomba E, Karita E, Mwananyanda L, Vwalika C, Conkling M, Luisi N, Tichacek A, Allen S. Is the reduction of HIV transmission risk while prescribed antiretroviral therapy (ARVT) different for men and women? Results from discordant couples in Rwanda and Zambia.. 5th International AIDS Society Conference on HIV Pathogenesis and Treatment and Prevention. Abstract Number 2009' WEAC101. Cape Town, July 2009.

\section{References to studies excluded from this review}

Baeten 2010 \{published data only\}

Baeten J, Donnell D, Kapiga S, Ronald A, et al.Male circumcision and risk of male-to-female HIV-1 transmission: a multinational prospective study in African HIV-1 serodiscordant couples. AIDS 2010;24:737-744.

Barreiro 2006 \{published data only\} Barreiro P, del Romero J, Leal M, et al.Natural pregnancies in HIV-serodiscordant couples receiving successful antiretroviral therapy.. AIDS 2006;20:85-92.

Brill 2003 \{published data only\} Brill I, Macaluso M, the Rwanda/Zambia HIV Research Group. A SAS program for the computation of seroconversion rates in a prospective study of HIV discordant couples in Lusaka, Zambia [Poster Abstract no. 
1130].. 2nd IAS Conference on HIV Pathogenesis and Treatment, Paris, France. 13-16 July 2003.

Bunnell 2006 \{published data only\}

Bunnell R, Ekwaru JP, Solberg P, et al.Changes in sexual behavior and risk of HIV transmission after antiretroviral therapy and prevention interventions in rural Uganda.. AIDS 2006;20:85-92.

\section{Bunnell 2008 \{published data only\}}

Bunnell R, Ekwaru JP, King R, Bechange S, Moore D, Khana K, et al.3-year follow-up of sexual behavior and HIV transmission risk of persons taking ART in rural Uganda. 15th Conference on Retroviruses and Opportunistic Infections. Boston, USA. 3-6 February 2008.

Fideli 2001 \{published data only\} Fideli US, Allen SA, Musonda R, Trask S, Hahn BH, Weiss $\mathrm{H}$, et al.Virologic and immunologic determinants of heterosexual transmission of human immunodefciency virus type 1 in Africa.. AIDS Res Hum Retroviruses 2001;17: 901-910.

Gray 2001 \{published data only\} Gray RH, Wawer MJ, Brookmeyer R, Sewankambo NK, Serwadda D, Wabwire-Mangen F, et al.Probability of HIV1 transmission per coital act in monogamous, heterosexual HIV-1-discordant couples in Rakai, Uganda.. Lancet 2001; 357:1149-53.

Kayitenkore 2006 \{published data only\} Kayitenkore K, Bekan B, Rufagari J, Marion-Landais S, Karita E, Allen S. The impact of ART on HIV transmission among HIV serodiscordant couples [Abstract no. MOKC101]. XVI International AIDS Conference, Toronto, Canada. 13-18 August 2006.

Mehendale 2004 \{published data only\} Mehendale SM, Kishore Kumar B, Ghate MV, Sahay S, Gamble T, Godbole SV, et al.Low HIV incidence in HIV sero-discordant couples in Pune, India [Abstract no. MoPeC3462]. XV International AIDS Conference, Bangkok, Thailand. 11-16 2004.

Operskalski 1997 \{published data only\} Operskalski EA, Stram DO, Busch MP, Huang W, Harris $\mathrm{M}$, Dietrich SL, et al.Role of viral load in heterosexual transmission of human immunodeficiency virus type 1 by blood transfusion recipients.. Am J Epidemiol 1997;146: 655-661.

Peters 2008 \{published data only\} Peters P, Zulu I, Kancheya N, et al.Modified Kigali Combined Staging Predicts Risk of Mortality in HIVInfected Adults in Lusaka, Zambia. AIDS Research and Human Retroviruses 2008;24(7):919.

Peterson 2007 \{published data only\}

Peterson L, Nanda K, Kofi Opoku B, et al.SAVVY Gel for Prevention of HIV infection in women: a Phase 3, doubleblind, randomised placebo-controlled trial in Ghana. PLoS ONE 2007;2(212):e1312.
Quinn 2000 \{published data only\}

Quinn TC, Wawer MJ, Sewankambo N, et al.Viral load and heterosexual transmission of human immunodeficiency virus type 1.. N Engl J Med 2000;342:921-29.

Ragni 1998 \{published data only\} Ragni MV, Faruki H, Kingsley LA. Heterosexual HIV1 transmission and viral load in hemophilic patients. $J$ Acquir Immune Defic Syndr Hum Retrovirol 1998;17:42-45.

Tovanabutra 2002 \{published data only\}

Tovanabutra S, Robison V, Wongtrakul J, Sennum S, Suriyanon V, Kingkeow D, et al.Male viral load and heterosexual transmission of HIV-1 subtype $\mathrm{E}$ in northern Thailand.. J Acquir Immune Defic Syndr 2002;29:275-283.

Wawer 2005 \{published data only\} Wawer MJ, Gray RH, Sewankambo NK, Serwadda D, Li $\mathrm{X}$, Laeyendecker O, et al.Rates of HIV-1transmission per coital act by stage of HIV-1 infection in Rakai, Uganda.. J Infect Dis 2005;191:1403-09.

\section{Additional references}

Altman 2003

Altman D, Bland M. Interaction revisited: the difference between two estimates. BMJ 2003;326:219.

Attia 2009

Attia S, Egger M, Muller M, Zwahlen M, Low N. Sexual transmission of HIV according to viral load and antiretroviral therapy: systematic review and meta-analysis. AIDS 2009;23:1397-1404.

\section{Castilla 2005}

Castilla J, del Romero J, Hernando V, et al.Effectiveness of highly active antiretroviral therapy in reducing heterosexual transmission of HIV. J Acquir Immune Defic Syndr 2005; 40: 96-101.

\section{Cohen 2010}

Cohen MS, Gay CL. Treatment to prevent transmission of HIV-1. Clin Infect Dis 2010;50(Suppl 3):S85-S95.

\section{Das 2010}

Das M, Chu PL, Santos GM, Scheer S, Vittinghoff E, McFarland W, Colfax GN. Decreases in community viral load are accompanied by reductions in new HIV infections in San Francisco. PLoS One 2010;5:e11068.

\section{Donnell 2009}

Donnell D, Kiarie J, Thomas K, et al.ART and risk of heterosexual HIV-1 transmission in HIV-1 serodiscordant African couples: a multinational prospective study.. 17th Conference on Retroviruses and Opportunistic Infections. San Francisco, 2009.

Dunkle 2008

Dunkle KL, Stephenson R, Karita E, et al.New heterosexually transmitted HIV infections in married or cohabiting couples in urban Zambia and Rwanda: an analysis of survey and clinical data. Lancet 2008;371: 2183-91.

\section{Eshleman 2011}

Eshleman S, Hudelson S, Redd A, et al.Analysis of Genetic Linkage of HIV From Couples Enrolled in the HIV 
Prevention Trials Network 052 Trial. The Journal of

Infectious Diseases 2011;204:1918-26.

Fang 2004

Fang CT, Hsu HM, Twu SJ, Chen MY, Chang YY, Hwang JS, Wang JD, Chuang CY. Decreased HIV transmission after a policy of providing free access to highly active antiretroviral therapy in Taiwan. J Infect Dis 2004;195(5): $879-85$.

Gill 2010

Gill VS, Lima VD, Zhang W. Improved virological outcomes in British Columbia concomitant with decreasing incidence of HIV type 1 drug resistance detection. Clin Infect Dis 2010;50:98-105.

\section{GRADEpro 2008}

Schünemann H, Brozek J, Oxman A. GRADEpro. GRADE Working Group, 2008.

\section{Granich 2009}

Granich RM, Gilks CF, Dye C, De Cock KM, Williams BG. Universal voluntary HIV testing with immediate antiretroviral therapy as a strategy for elimination of HIV transmission: a mathematical model. Lancet 2009;373: $48-58$.

\section{Grant 2010}

Grant RM. Antiretroviral agents used by HIV-uninfected persons for prevention: pre- and postexposure prophylaxis. Clin Infect Dis 2010;50(Suppl 3):S96-101.

\section{Grinsztejn 2011}

Grinsztejn B, Smeaton L, Barnett R, Klingman K, Hakim J, Flanigan T, Kumarasamy N, Campbell T, Currier J, PEARLS study team of the ACTG. Sex-associated differences in pre-antiretroviral therapy plasma HIV-1 RNA in diverse areas of the world vary by CD4(+) T-cell count. Antiviral Therapy 2011;16(7):1057-62.

\section{Guyatt 2008}

Guyatt GH, Oxman AD, Vist GE, Kunz R, Falck-Ytter Y, Alonso-Coello P, Schunemann HJ, GRADE Working Group. GRADE: an emerging consensus on rating quality of evidence and strength of recommendations. BMJ 2008; 336(7650):924-6.

\section{Hallett 2011}

Hallett T, Smit C, Garnett G, de Wolf F. Estimating the risk of HIV transmission from homosexual men receiving treatment to their HIV-uninfected partners. Sex Transm Infect 2011;87:17-21.

Higgins 2008

Higgins JPT, Green S (editors). Cochrane Handbook for Systematic Reviews of Interventions. Chichester: John Wiley $\&$ Sons Ltd, 2008

\section{HPTN 2011}

HIV Prevention Trials Network. HPTN 052: a randomized trial to evaluate the effectiveness of antiretroviral therapy plus HIV primary care versus HIV primary care alone to prevent the sexual transmission of HIV-1 serodiscordant couples. HPTN 052 protocol. Available at http://www.hptn.org/ research studies/HPTN052StudyDocuments.asp\#Protocol. Accessed 19 May 2011.

\section{Jourdain 2007}

Jourdain G, Mary JY, Coeur SL, Ngo-Giang-Huong N, Yuthavisuthi P, Limtrakul A, Traisathit P, McIntosh K, Lallemant M, Perinatal HIV Prevention Trial Group, Thailand. Risk factors for in utero or intrapartum motherto-child transmission of human immunodeficiency virus type 1 in Thailand. J Infect Dis 2007;196:1629-36.

\section{Lorella 2009}

Lorella G, la Porte C, Pilon R, Zhang G, Karnauchow T, MacPherson P. Discordance in HIV-1 viral loads and antiretroviral drug concentrations among semen and blood plasma. HIV Med 2009;10:548-54.

Mermin 2008

Mermin J, Musinguzi J, Opio A, et al.Risk factors for recent HIV infection in Uganda. JAMA 2008;300:540-49.

\section{Miller 2010}

Miller WC, Rosenberg NE, Rutstein SE, Powers KA. Role of acute and early HIV infection in the sexual transmission of HIV. Curr Opin HIV AIDS 2010;5:277-82.

\section{Montaner 2010}

Montaner JS, Lima VD, Barrios R, et al.Association of highly active antiretroviral therapy coverage, population viral load, and yearly new HIV diagnoses in British Columbia, Canada: a population-based study. Lancet 2010 Aug 14;376(9740):532-9.

\section{Newcastle-Ottawa}

Wells GA, Shea B, O'Connell D, Peterson J, Welch V, Losos M, Tugwell P. The Newcastle-Ottawa Scale (NOS) for assessing the quality of nonrandomised studies in metaanalyses. Available from: http://www.ohri.ca/programs/ clinical' epidemiology/oxford.htm.

Okwundu 2012

Okwundu CI, Uthman OA, Okoromah CA. Antiretroviral pre-exposure prophylaxis (PrEP) for preventing HIV in high-risk individuals. Cochrane Database of Systematic Reviews 2012, Issue 7. [PUBMED: 22786505]

Porco 2004

Porco T, Page-Shafer K, Cheng A, Charlebois E, Grant RM, Osmond DH. Decline in HIV infectivity following the introduction of highly active antiretroviral therapy.. AIDS 2004;18:81-88.

\section{Rothman 1998}

Rothman K, Greenland S. Modern Epidemiology. Second Edition. Philadelphia, PA: Lippincott Williams and Wilkins, 1998.

\section{Sheth 2009}

Sheth PM, Kovacs C, Kemal KS, Jones RB, Raboud JM, Pilon R, la Porte C, Ostrowski M, Loufty M, Burger H, Weiser B, Kaul R, Toronto Mucosal Immunology Group. Persistent HIV RNA shedding in semen despite effective antiretroviral therapy.. AIDS 2009;23:2050-54. 


\section{Siegfried 2011}

Siegfried N, van der Merwe L, Brocklehurst P, Sint TT. Antiretrovirals for reducing the risk of mother-to-child transmission of HIV infection. Cochrane Database of Systematic Reviews 2011, Issue 7. [PUBMED: 21735394]

UNAIDS 2009

Joint United Nations Programme on HIV/AIDS, World Health Organization. AIDS epidemic update: November 2009. WHO, Geneva, Switzerland.

Vettore 2006

Vettore MV, Schecter M, Melo MF, Coechat LJ, Barroso PF. Genital HIV-1 viral load is correlated with blood plasma HIV-1 viral load in Brazilian women and is reduced by antiretroviral therapy.. J Infect 2006;52:290-93.

WHO 2010

World Health Organization. Antiretroviral therapy for HIV infection in adults and adolescents: recommendations for a public health approach.. WHO, Geneva, Switzerland 2010.

\section{WHO 2012}

World Health Organization. Guidance on couples HIV testing and counselling, including antiretroviral therapy for treatmentand prevention in serodiscordant couples: recommendations for a public health approach. Available from http://www.who.int/hiv/pub/guidelines/ 9789241501972/en/index.html [accessed 28 February 2013]

\section{Wood 2009}

Wood E, Kerr T, Marshall B, et al.Longitudinal community plasma HIV-1 RNA concentrations and incidence of HIV1 among injecting drug users: prospective cohort study. BMJ 2009;338:b1659.

Young 2007

Young TN, Arens FJ, Kennedy GE, Laurie JW, Rutherford G. Antiretroviral post-exposure prophylaxis (PEP) for occupational HIV exposure.. Cochrane Database of Systematic Reviews 2007 Jan 24, Issue 1. [PUBMED: CD002835]

\section{References to other published versions of this review}

\section{Anglemyer 2011a}

Anglemyer A, Rutherford GW, Egger M, Siegfried N. Antiretroviral therapy for prevention of HIV transmission in HIV-discordant couples. Cochrane Database of Systematic Reviews 2011 May 11, Issue 5. [CENTRAL: CD009153][Art. No.: CD009153. DOI: 10.1002/ 14651858.CD009153.pub3]

Anglemyer 2011b

Anglemyer A, Rutherford George W, Baggaley Rachel C, Egger M, Siegfried N. Antiretroviral therapy for prevention of HIV transmission in HIV-discordant couples. Cochrane Database of Systematic Reviews. John Wiley \& Sons, Ltd, 2011, issue 8. [CENTRAL: CD009153]

* Indicates the major publication for the study 


\section{CHARACTERISTICS OF STUDIES}

\section{Characteristics of included studies [ordered by study ID]}

\section{Birungi 2012}

\begin{tabular}{lll}
\hline Methods & Observational cohort \\
\hline Participants & 550 heterosexual couples attending a clinic in Uganda \\
\hline Interventions & ART & \\
\hline Outcomes & Incident HIV Infection \\
\hline Notes & & \\
\hline Risk of bias & Authors' judgement & Support for judgement \\
\hline Bias & High risk & Non-randomised study \\
\hline $\begin{array}{l}\text { Random sequence generation (selection } \\
\text { bias) }\end{array}$ & High risk & Non-randomised study \\
\hline Allocation concealment (selection bias) & Non-randomised study \\
\hline $\begin{array}{l}\text { Blinding (performance bias and detection } \\
\text { bias) } \\
\text { All outcomes }\end{array}$ & High risk & \\
\hline $\begin{array}{l}\text { Incomplete outcome data (attrition bias) } \\
\text { All outcomes }\end{array}$ & Unclear risk & Study protocol was not available. Risk of bias unclear. \\
\hline $\begin{array}{l}\text { Selective reporting (reporting bias) } \\
\text { Other bias }\end{array}$ & Unclear risk & Study protocol was not available. Risk of bias unclear. \\
\hline
\end{tabular}

\section{Cohen 2011}

\begin{tabular}{ll}
\hline Methods & Randomised controlled trial \\
\hline Participants & $\begin{array}{l}1750 \text { serodiscordant couples enrolled in nine countries with CD4 counts from 350-550 } \\
\text { cells/ } \mu \mathrm{L}\end{array}$ \\
\hline Interventions & Immediate ART vs delayed ART until CD4 falls below 250 \\
\hline Outcomes & Incident HIV infection (all and virologically linked) \\
\hline Notes & \\
\hline
\end{tabular}

\section{Risk of bias}


Cohen 2011 (Continued)

\begin{tabular}{|c|c|c|}
\hline Bias & Authors' judgement & Support for judgement \\
\hline $\begin{array}{l}\text { Random sequence generation (selection } \\
\text { bias) }\end{array}$ & Low risk & $\begin{array}{l}\text { The method of sequence generation is not explicitly } \\
\text { stated but as permuted block randomisation with stratif- } \\
\text { cation was used, it is assumed this was done by computer } \\
\text { and we judged it to be at low risk of bias }\end{array}$ \\
\hline Allocation concealment (selection bias) & Unclear risk & $\begin{array}{l}\text { Random allocation in a } 1: 1 \text { ratio was performed in the } \\
\text { RCT. The article does not specify how allocation was } \\
\text { concealed }\end{array}$ \\
\hline $\begin{array}{l}\text { Blinding (performance bias and detection } \\
\text { bias) } \\
\text { All outcomes }\end{array}$ & Unclear risk & $\begin{array}{l}\text { Unblinded study but biological endpoints make bias less } \\
\text { likely }\end{array}$ \\
\hline $\begin{array}{l}\text { Incomplete outcome data (attrition bias) } \\
\text { All outcomes }\end{array}$ & Low risk & No evidence of attrition bias. \\
\hline Selective reporting (reporting bias) & Low risk & No evidence of reporting bias. \\
\hline Other bias & Low risk & No evidence of other bias. \\
\hline
\end{tabular}

\section{Del Romero 2010}

\begin{tabular}{|c|c|c|}
\hline Methods & \multicolumn{2}{|l|}{ Observational cohort } \\
\hline Participants & \multicolumn{2}{|c|}{648 heterosexual couples attending a clinic in Madrid, Spain, from 1989 to 2008} \\
\hline Interventions & \multicolumn{2}{|l|}{ ART } \\
\hline Outcomes & \multicolumn{2}{|l|}{ Incident HIV Infection } \\
\hline \multicolumn{3}{|l|}{ Notes } \\
\hline \multicolumn{3}{|l|}{ Risk of bias } \\
\hline Bias & Authors' judgement & Support for judgement \\
\hline $\begin{array}{l}\text { Random sequence generation (selection } \\
\text { bias) }\end{array}$ & High risk & Non-randomised study \\
\hline Allocation concealment (selection bias) & High risk & Non-randomised study \\
\hline $\begin{array}{l}\text { Blinding (performance bias and detection } \\
\text { bias) } \\
\text { All outcomes }\end{array}$ & High risk & Non-randomised study \\
\hline
\end{tabular}


Del Romero 2010 (Continued)

\begin{tabular}{l|l|l}
\hline $\begin{array}{l}\text { Incomplete outcome data (attrition bias) } \\
\text { All outcomes }\end{array}$ & Low risk & Complete follow-up. All subjects accounted for. \\
\hline Selective reporting (reporting bias) & Low risk & No evidence of reporting bias. \\
\hline Other bias & Low risk & No evidence of other bias. \\
\hline
\end{tabular}

\section{Donnell 2010}

\begin{tabular}{|c|c|c|}
\hline Methods & \multicolumn{2}{|l|}{ Observational cohort } \\
\hline Participants & \multicolumn{2}{|c|}{$\begin{array}{l}\text { Heterosexual African adults who were seropositive for both HIV and herpes simplex } \\
\text { virus type II (HSV-2) and their HIV-uninfected sexual partners. Three thousand four } \\
\text { hundred eight couples were enrolled from seven countries (Botswana, Kenya, Rwanda, } \\
\text { South Africa, Tanzania, Uganda, and Zambia) }\end{array}$} \\
\hline Interventions & \multicolumn{2}{|l|}{ ART } \\
\hline Outcomes & \multicolumn{2}{|l|}{ Incident HIV Infection } \\
\hline \multicolumn{3}{|l|}{ Notes } \\
\hline \multicolumn{3}{|l|}{ Risk of bias } \\
\hline Bias & Authors' judgement & Support for judgement \\
\hline $\begin{array}{l}\text { Random sequence generation (selection } \\
\text { bias) }\end{array}$ & High risk & Non-randomised study \\
\hline Allocation concealment (selection bias) & High risk & Non-randomised study \\
\hline $\begin{array}{l}\text { Blinding (performance bias and detection } \\
\text { bias) } \\
\text { All outcomes }\end{array}$ & High risk & Non-randomised study \\
\hline $\begin{array}{l}\text { Incomplete outcome data (attrition bias) } \\
\text { All outcomes }\end{array}$ & Low risk & Subjects lost to follow up discussed. \\
\hline Selective reporting (reporting bias) & Low risk & No evidence of reporting bias. \\
\hline Other bias & Low risk & No evidence of other bias. \\
\hline
\end{tabular}


Jia 2012

\begin{tabular}{|c|c|c|}
\hline Methods & \multicolumn{2}{|c|}{$\begin{array}{l}\text { National-level data of HIV testing and treatment from the National Centre for AIDS/ } \\
\text { STD Control and Prevention }\end{array}$} \\
\hline Participants & \multicolumn{2}{|c|}{ All individuals in China who have tested positive for HIV } \\
\hline Interventions & \multicolumn{2}{|l|}{ ART } \\
\hline Outcomes & \multicolumn{2}{|l|}{ HIV incidence } \\
\hline \multicolumn{3}{|l|}{ Notes } \\
\hline \multicolumn{3}{|l|}{ Risk of bias } \\
\hline Bias & Authors' judgement & Support for judgement \\
\hline $\begin{array}{l}\text { Random sequence generation (selection } \\
\text { bias) }\end{array}$ & High risk & Non-randomised study \\
\hline Allocation concealment (selection bias) & High risk & Non-randomised study \\
\hline $\begin{array}{l}\text { Blinding (performance bias and detection } \\
\text { bias) } \\
\text { All outcomes }\end{array}$ & High risk & Non-randomised study \\
\hline $\begin{array}{l}\text { Incomplete outcome data (attrition bias) } \\
\text { All outcomes }\end{array}$ & Low risk & $\begin{array}{l}\text { Subjects lost to follow up or with missing } \\
\text { data were discussed }\end{array}$ \\
\hline Selective reporting (reporting bias) & Unclear risk & $\begin{array}{l}\text { Study protocol was not available. Risk of } \\
\text { bias unclear. }\end{array}$ \\
\hline Other bias & Unclear risk & No statement \\
\hline
\end{tabular}

Lu 2010

Methods Observational cohort

Participants

1927 heterosexual couples between January 2006 and December 2008 for testing and treatment at county hospitals in China

\begin{tabular}{ll} 
Interventions & ART \\
\hline Outcomes & Incident HIV Infection
\end{tabular}

Notes

Risk of bias

Bias

Authors' judgement Support for judgement 
Lu 2010 (Continued)

\begin{tabular}{|c|c|c|}
\hline $\begin{array}{l}\text { Random sequence generation (selection } \\
\text { bias) }\end{array}$ & High risk & Non-randomised study \\
\hline Allocation concealment (selection bias) & High risk & Non-randomised study \\
\hline $\begin{array}{l}\text { Blinding (performance bias and detection } \\
\text { bias) } \\
\text { All outcomes }\end{array}$ & High risk & Non-randomised study \\
\hline $\begin{array}{l}\text { Incomplete outcome data (attrition bias) } \\
\text { All outcomes }\end{array}$ & Unclear risk & Study protocol was not available. Risk of bias unclear. \\
\hline Selective reporting (reporting bias) & Unclear risk & Study protocol was not available. Risk of bias unclear. \\
\hline Other bias & Low risk & $\begin{array}{l}\text { Though unknown in what direction, bias is potentially present } \\
\text { as a result of unavailable person-time data for treated and un- } \\
\text { treated couples }\end{array}$ \\
\hline
\end{tabular}

Melo 2008

\begin{tabular}{ll}
\hline Methods & Observational cohort \\
\hline Participants & $\begin{array}{l}93 \text { discordant couples, in which the female member of the couple was infected in } 67 \\
(72 \%) \text { and the male in } 26(28 \%)\end{array}$ \\
\hline Interventions & ART \\
\hline Outcomes & Incident HIV Infection \\
\hline Notes & \\
\hline
\end{tabular}

\section{Risk of bias}

\begin{tabular}{|c|c|c|}
\hline Bias & Authors' judgement & Support for judgement \\
\hline $\begin{array}{l}\text { Random sequence generation (selection } \\
\text { bias) }\end{array}$ & High risk & Non-randomised study \\
\hline Allocation concealment (selection bias) & High risk & Non-randomised study \\
\hline $\begin{array}{l}\text { Blinding (performance bias and detection } \\
\text { bias) } \\
\text { All outcomes }\end{array}$ & High risk & Non-randomised study \\
\hline $\begin{array}{l}\text { Incomplete outcome data (attrition bias) } \\
\text { All outcomes }\end{array}$ & Low risk & Subjects lost to follow up discussed. \\
\hline Selective reporting (reporting bias) & Low risk & No evidence of reporting bias. \\
\hline
\end{tabular}


Melo 2008 (Continued)

Other bias $\quad$ Low risk No evidence of other bias.

Musicco 1994

\begin{tabular}{|c|c|c|}
\hline Methods & \multicolumn{2}{|l|}{ Observational cohort } \\
\hline Participants & \multicolumn{2}{|c|}{$\begin{array}{l}\text { A cohort of } 436 \text { monogamous HIV-uninfected female sexual partners of HIV-infected } \\
\text { men recruited from } 16 \text { centres in Italy }\end{array}$} \\
\hline Interventions & \multicolumn{2}{|l|}{ Zidovudine } \\
\hline Outcomes & \multicolumn{2}{|l|}{ Incident HIV Infection } \\
\hline \multicolumn{3}{|l|}{ Notes } \\
\hline \multicolumn{3}{|l|}{ Risk of bias } \\
\hline Bias & Authors' judgement & Support for judgement \\
\hline $\begin{array}{l}\text { Random sequence generation (selection } \\
\text { bias) }\end{array}$ & High risk & Non-randomised study \\
\hline Allocation concealment (selection bias) & High risk & Non-randomised study \\
\hline $\begin{array}{l}\text { Blinding (performance bias and detection } \\
\text { bias) } \\
\text { All outcomes }\end{array}$ & High risk & Non-randomised study \\
\hline $\begin{array}{l}\text { Incomplete outcome data (attrition bias) } \\
\text { All outcomes }\end{array}$ & Unclear risk & Study protocol was not available. Risk of bias unclear. \\
\hline Selective reporting (reporting bias) & Low risk & No evidence of reporting bias. \\
\hline Other bias & Low risk & No evidence of other bias. \\
\hline
\end{tabular}

Reynolds 2011

\begin{tabular}{ll}
\hline Methods & Observational cohort \\
\hline Participants & 250 HIV-discordant couples from Rakai, Uganda. \\
\hline Interventions & ART \\
\hline Outcomes & Incident HIV Infection \\
\hline Notes & \\
\hline
\end{tabular}

\section{Risk of bias}


Reynolds 2011 (Continued)

\begin{tabular}{l|l|l}
\hline Bias & Authors judgement & Support for judgement \\
\hline $\begin{array}{l}\text { Random sequence generation (selection } \\
\text { bias) }\end{array}$ & High risk & Non-randomised study \\
\hline $\begin{array}{l}\text { Allocation concealment (selection bias) } \\
\text { Blinding (performance bias and detection } \\
\text { bias) } \\
\text { All outcomes }\end{array}$ & High risk & Non-randomised study \\
\hline $\begin{array}{l}\text { Incomplete outcome data (attrition bias) } \\
\text { All outcomes }\end{array}$ & Unclear risk & Non-randomised study \\
\hline \begin{tabular}{l} 
Selective reporting (reporting bias) \\
\hline Other bias
\end{tabular} & Low risk & Study protocol was not available. Risk of bias unclear. \\
\hline
\end{tabular}

\section{Sullivan 2009}

\begin{tabular}{l|l}
\hline Methods & Observational cohort \\
\hline Participants & 2,993 HIV-discordant couples in Rwanda and Zambia followed from 2002 to 2008 \\
\hline Interventions & ART \\
\hline Outcomes & Incident HIV Infection \\
\hline Notes & \\
\hline
\end{tabular}

\section{Risk of bias}

\begin{tabular}{|c|c|c|}
\hline Bias & Authors' judgement & Support for judgement \\
\hline $\begin{array}{l}\text { Random sequence generation (selection } \\
\text { bias) }\end{array}$ & High risk & Non-randomised study \\
\hline Allocation concealment (selection bias) & High risk & Non-randomised study \\
\hline $\begin{array}{l}\text { Blinding (performance bias and detection } \\
\text { bias) } \\
\text { All outcomes }\end{array}$ & High risk & Non-randomised study \\
\hline $\begin{array}{l}\text { Incomplete outcome data (attrition bias) } \\
\text { All outcomes }\end{array}$ & Unclear risk & Study protocol was not available. Risk of bias unclear. \\
\hline Selective reporting (reporting bias) & Low risk & No evidence of reporting bias. \\
\hline
\end{tabular}


Sullivan 2009 (Continued)

Other bias

Low risk

No evidence of other bias.

Characteristics of excluded studies [ordered by study ID]

\begin{tabular}{|c|c|}
\hline Study & Reason for exclusion \\
\hline Baeten 2010 & ART was not given \\
\hline Barreiro 2006 & All index cases received ART \\
\hline Brill 2003 & ART was not given \\
\hline Bunnell 2006 & All index cases received ART \\
\hline Bunnell 2008 & All index cases received ART \\
\hline Fideli 2001 & ART was not given \\
\hline Gray 2001 & ART was not given \\
\hline Kayitenkore 2006 & ART was not given \\
\hline Mehendale 2004 & ART was not given \\
\hline Operskalski 1997 & ART was not given \\
\hline Peters 2008 & ART was not given \\
\hline Peterson 2007 & ART was not given \\
\hline Quinn 2000 & ART was not given \\
\hline Ragni 1998 & ART was not given \\
\hline Tovanabutra 2002 & ART was not given \\
\hline Wawer 2005 & ART was not given \\
\hline
\end{tabular}


DATA ANDANALYSES

Comparison 1. Delayed vs Immediate ART (RCTs)

\begin{tabular}{|c|c|c|c|c|}
\hline Outcome or subgroup title & $\begin{array}{l}\text { No. of } \\
\text { studies }\end{array}$ & $\begin{array}{c}\text { No. of } \\
\text { participants }\end{array}$ & Statistical method & Effect size \\
\hline 1 Linked Incident HIV Infection & 1 & & Rate Ratio (Fixed, 95\% CI) & $0.04[0.00,0.27]$ \\
\hline 2 All Incident HIV Infection & 1 & & Rate Ratio (Fixed, 95\% CI) & $0.11[0.04,0.32]$ \\
\hline $\begin{array}{l}3 \text { Severe or Life-Threatening } \\
\text { Adverse Events (Grade } 3 \text { or 4) }\end{array}$ & 1 & 1763 & Risk Ratio (M-H, Fixed, 95\% CI) & $1.06[0.84,1.33]$ \\
\hline $\begin{array}{l}4 \text { Grade } 3 \text { or } 4 \text { Laboratory } \\
\text { Abnormalities }\end{array}$ & 1 & 1763 & Risk Ratio (M-H, Fixed, 95\% CI) & $1.49[1.25,1.77]$ \\
\hline
\end{tabular}

Comparison 2. Treated with ART vs Not Treated with ART (Observational Studies)

\begin{tabular}{lcccc} 
Outcome or subgroup title & $\begin{array}{c}\text { No. of } \\
\text { studies }\end{array}$ & $\begin{array}{c}\text { No. of } \\
\text { participants }\end{array}$ & Statistical method & Effect size \\
\hline 1 Incident HIV Infection & 9 & & Rate Ratio (Random, 95\% CI) & $0.58[0.35,0.96]$ \\
\hline
\end{tabular}

Comparison 3. Treated with ART vs Not Treated with ART (Observational Studies, sensitivity analysis)

\begin{tabular}{lcccc} 
Outcome or subgroup title & $\begin{array}{c}\text { No. of } \\
\text { studies }\end{array}$ & $\begin{array}{c}\text { No. of } \\
\text { participants }\end{array}$ & Statistical method & Effect size \\
\hline 1 Incident HIV Infection & 7 & & Rate Ratio (Random, 95\% CI) & $0.36[0.17,0.75]$ \\
\hline
\end{tabular}

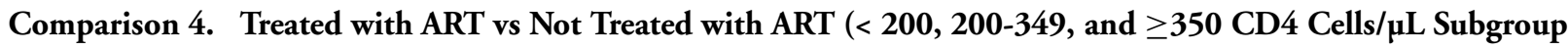
Analysis) (Observational Studies)

\begin{tabular}{|c|c|c|c|c|}
\hline Outcome or subgroup title & $\begin{array}{l}\text { No. of } \\
\text { studies }\end{array}$ & $\begin{array}{c}\text { No. of } \\
\text { participants }\end{array}$ & Statistical method & Effect size \\
\hline 1 Incident HIV Infection & 5 & & Rate Ratio (Random, 95\% CI) & Subtotals only \\
\hline 1.1 Less than 200 CD4 & 5 & & Rate Ratio (Random, 95\% CI) & $0.12[0.02,0.81]$ \\
\hline $1.2200-350 \mathrm{CD} 4$ & 4 & & Rate Ratio (Random, 95\% CI) & $0.66[0.47,0.92]$ \\
\hline 1.3 More than 350 CD4 & 3 & & Rate Ratio (Random, 95\% CI) & $0.12[0.01,1.99]$ \\
\hline
\end{tabular}


Comparison 5. Treated with ART vs Not Treated with ART (Female/Male Subgroup Analysis) (Observational Studies)

\begin{tabular}{|c|c|c|c|c|}
\hline Outcome or subgroup title & $\begin{array}{l}\text { No. of } \\
\text { studies }\end{array}$ & $\begin{array}{c}\text { No. of } \\
\text { participants }\end{array}$ & Statistical method & Effect size \\
\hline 1 Incident HIV Infection & 3 & & Risk Ratio (Random, 95\% CI) & Subtotals only \\
\hline 1.1 Female Index Case & 3 & & Risk Ratio (Random, 95\% CI) & $0.39[0.13,1.18]$ \\
\hline 1.2 Male Index Case & 3 & & Risk Ratio (Random, 95\% CI) & $0.11[0.01,1.62]$ \\
\hline
\end{tabular}

Comparison 6. Treated with ART vs Not Treated with ART (Subgroup Analysis: Low-/Middle-Income vs Highincome)) (Observational Studies)

\begin{tabular}{|c|c|c|c|c|}
\hline Outcome or subgroup title & $\begin{array}{l}\text { No. of } \\
\text { studies }\end{array}$ & $\begin{array}{c}\text { No. of } \\
\text { participants }\end{array}$ & Statistical method & Effect size \\
\hline 1 Incident HIV Infection & 9 & & Rate Ratio (Random, 95\% CI) & Subtotals only \\
\hline 1.1 Low/Middle Income & 7 & & Rate Ratio (Random, 95\% CI) & $0.53[0.29,0.97]$ \\
\hline \multicolumn{5}{|l|}{ Country } \\
\hline 1.2 High Income Country & 2 & & Rate Ratio (Random, 95\% CI) & $0.77[0.33,1.83]$ \\
\hline
\end{tabular}

\section{Analysis I.I. Comparison I Delayed vs Immediate ART (RCTs), Outcome I Linked Incident HIV Infection.}

Review: Antiretroviral therapy for prevention of HIV transmission in HIV-discordant couples

Comparison: I Delayed vs Immediate ART (RCTs)

Outcome: I Linked Incident HIV Infection

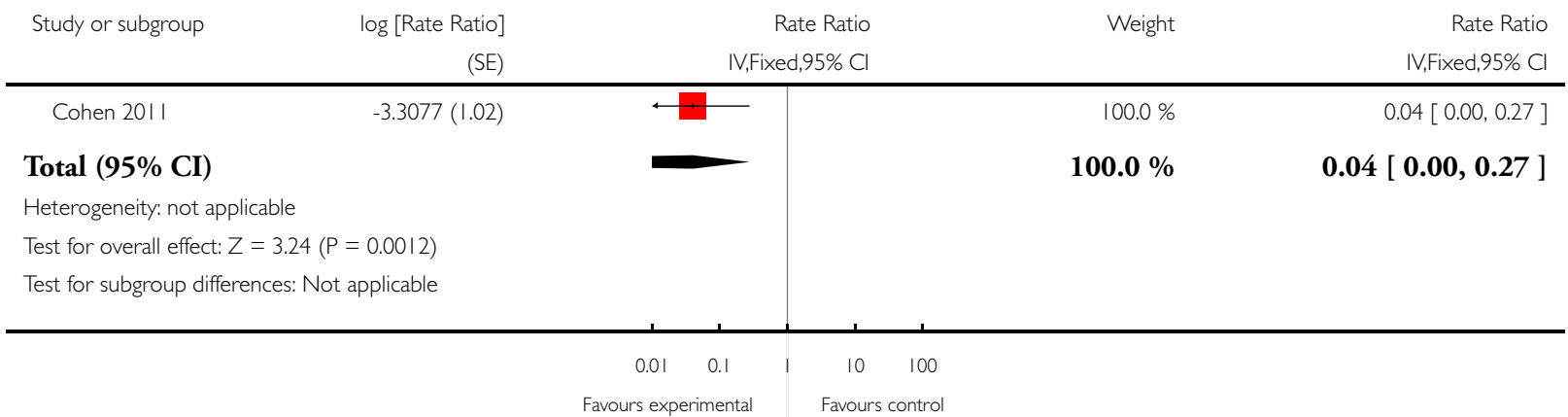


Analysis I.2. Comparison I Delayed vs Immediate ART (RCTs), Outcome 2 All Incident HIV Infection.

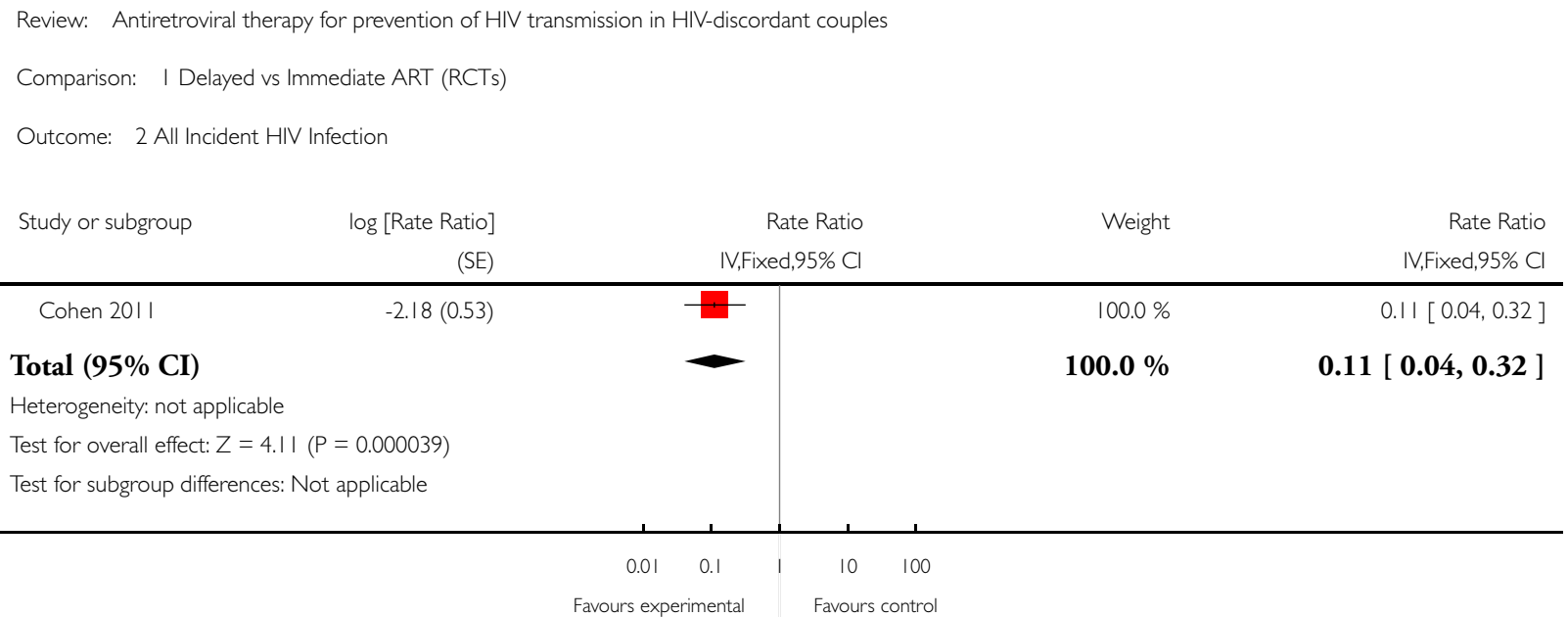

\section{Analysis I.3. Comparison I Delayed vs Immediate ART (RCTs), Outcome 3 Severe or Life-Threatening Adverse Events (Grade 3 or 4 ).}

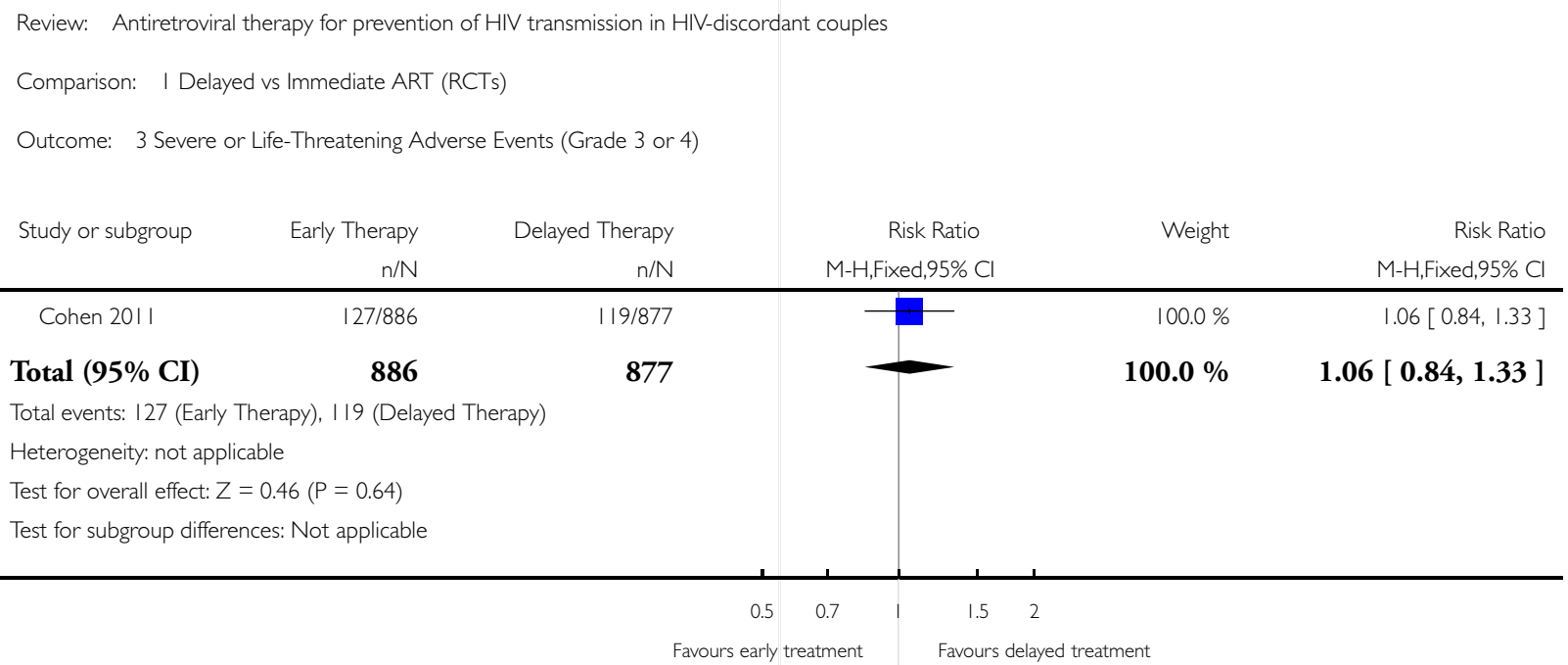


Analysis I.4. Comparison I Delayed vs Immediate ART (RCTs), Outcome 4 Grade 3 or 4 Laboratory Abnormalities.

Review: Antiretroviral therapy for prevention of HIV transmission in HIV-discordant couples

Comparison: I Delayed vs Immediate ART (RCTs)

Outcome: 4 Grade 3 or 4 Laboratory Abnormalities

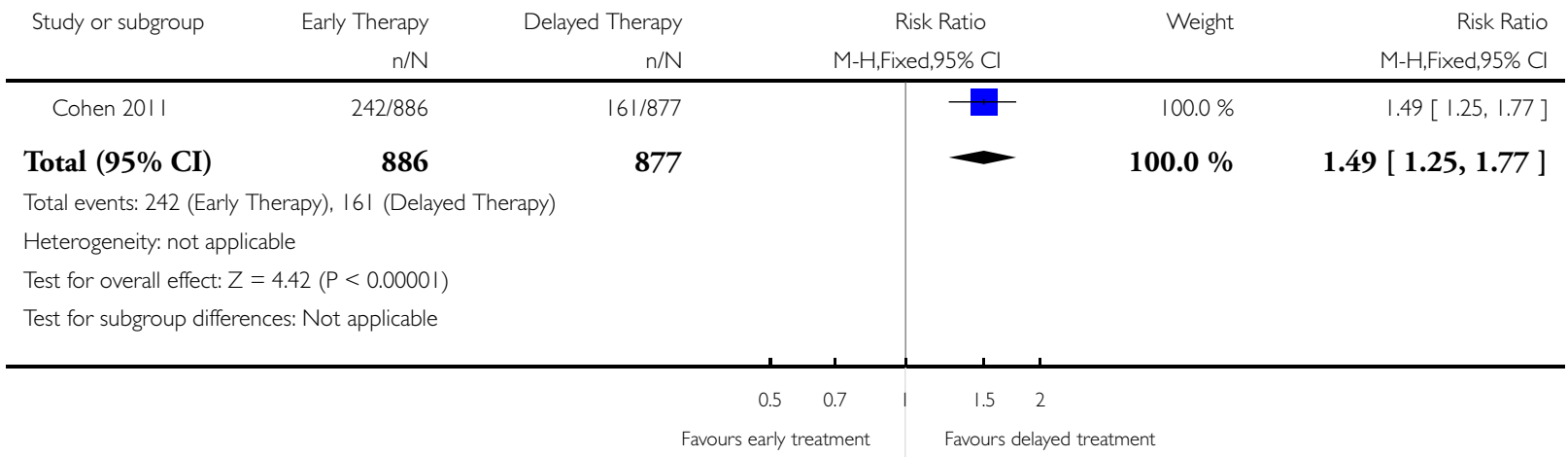




\section{Analysis 2.I. Comparison 2 Treated with ART vs Not Treated with ART (Observational Studies), Outcome I Incident HIV Infection.}

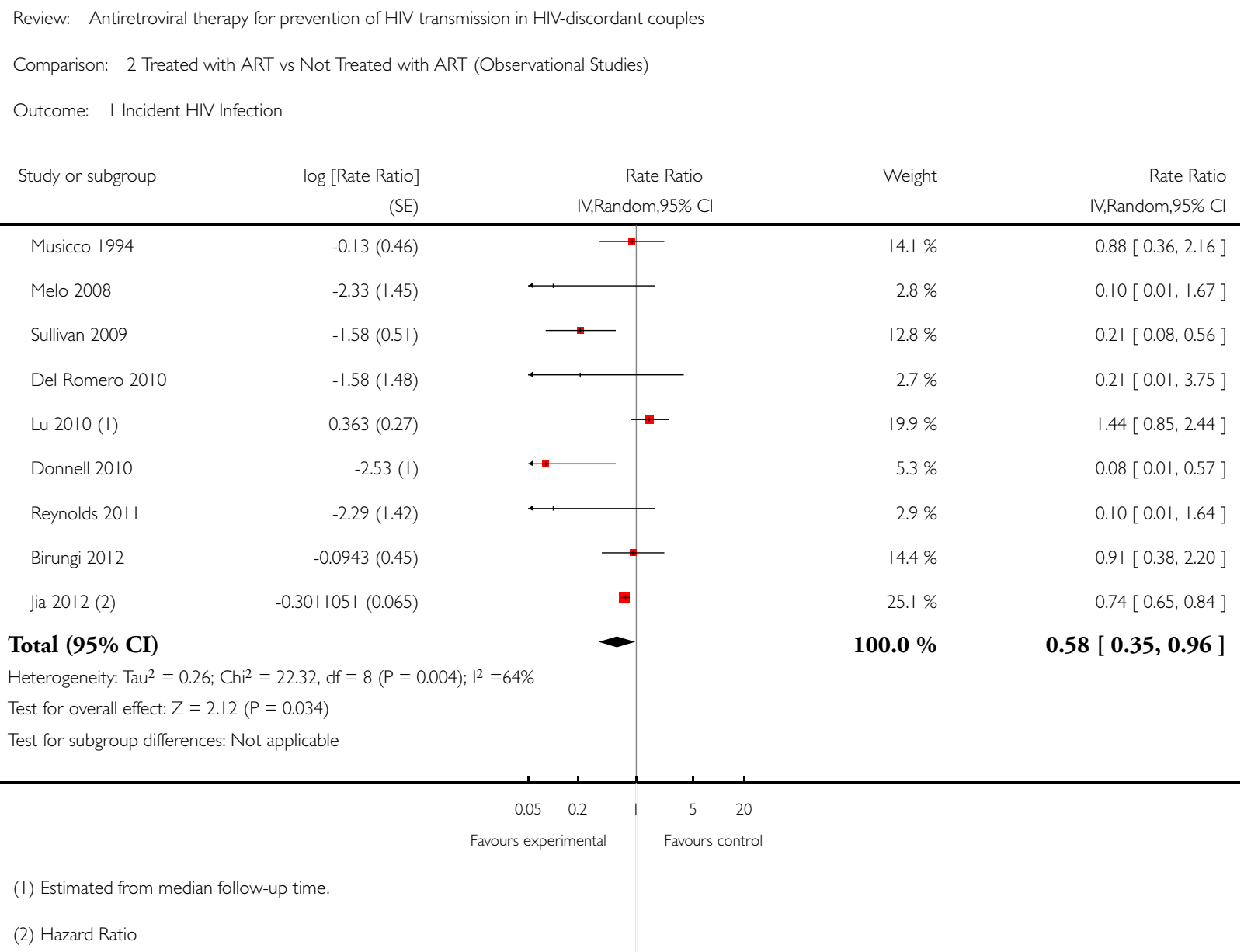




\section{Analysis 3.I. Comparison 3 Treated with ART vs Not Treated with ART (Observational Studies, sensitivity}

analysis), Outcome I Incident HIV Infection.

Review: Antiretroviral therapy for prevention of HIV transmission in HIV-discordant couples

Comparison: 3 Treated with ART vs Not Treated with ART (Observational Studies, sensitivity analysis)

Outcome: I Incident HIV Infection

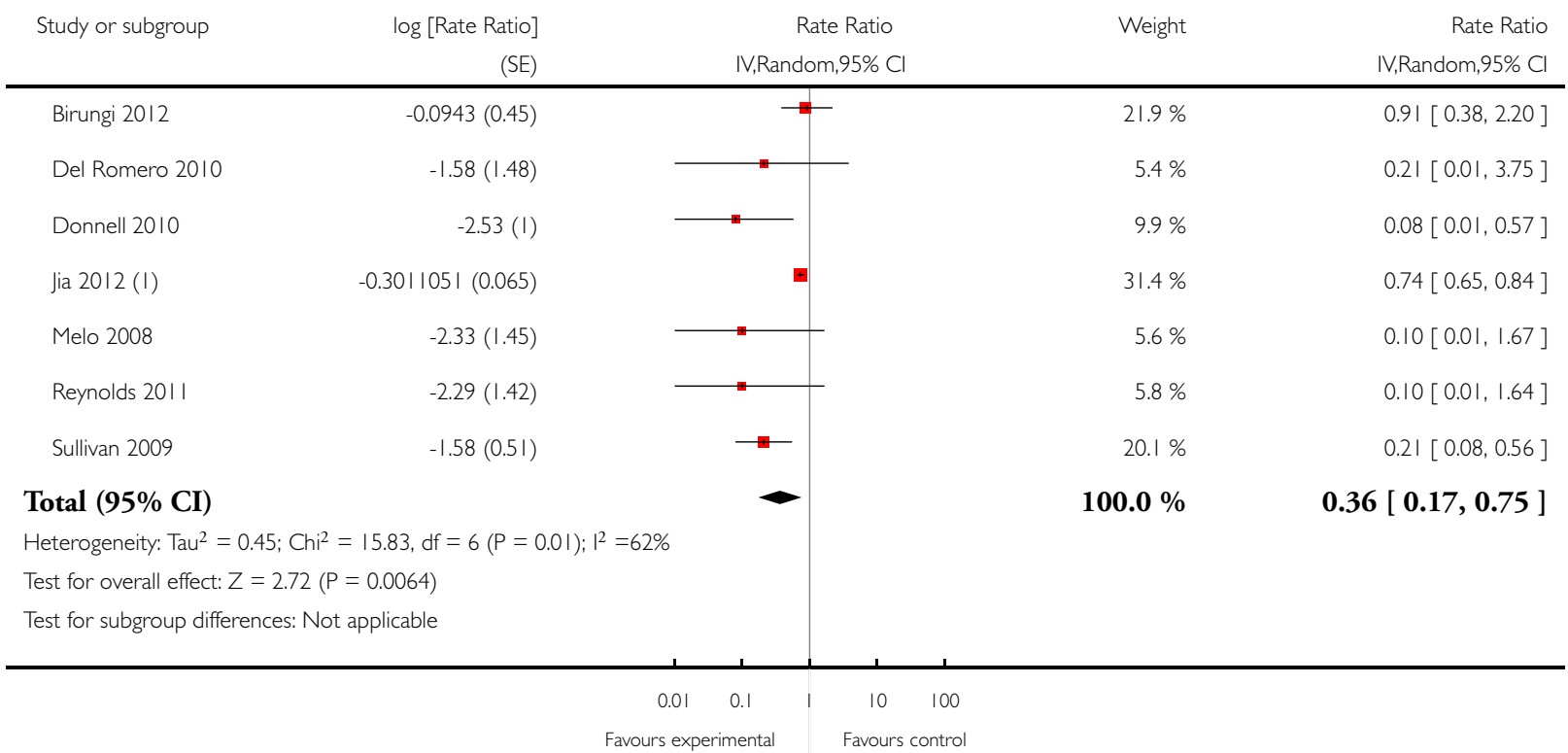

( I) Hazard Ratio 
Analysis 4.I. Comparison 4 Treated with ART vs Not Treated with ART (<200, 200-349, and $\geq 350$ CD4

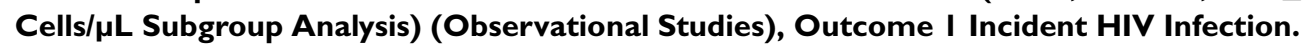

Review: Antiretroviral therapy for prevention of HIV transmission in HIV-discordant couples

Comparison: 4 Treated with ART vs Not Treated with ART (<200, 200-349, and $\geq 350$ CD4 Cells/ L Subgroup Analysis) (Observational Studies)

Outcome: I Incident HIV Infection

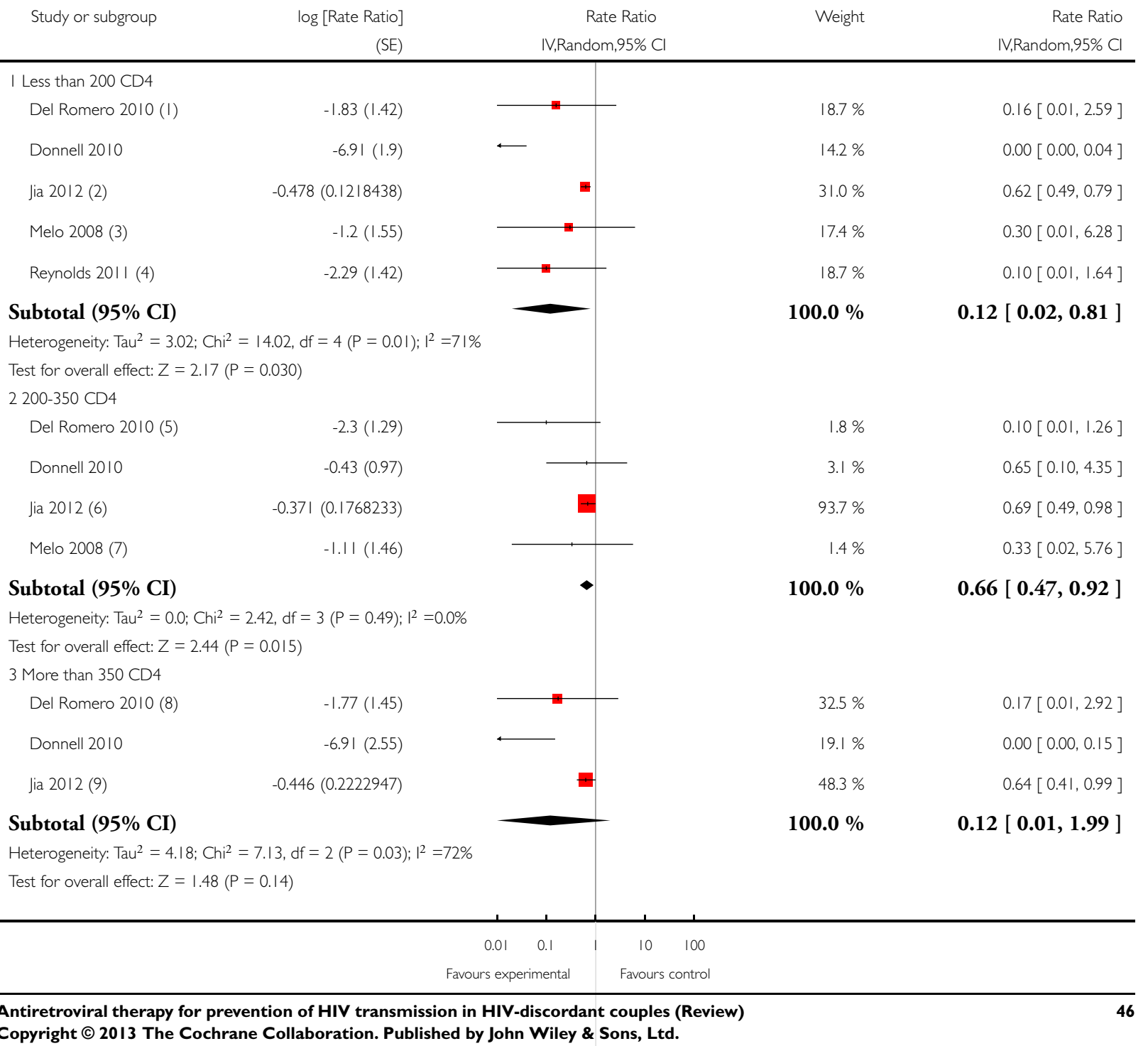



(I) Risk ratio.
(2) HR; CD4 $<250$
(3) 0/8 treated subjects whose CD4 < 350. Risk Ratio.
(4) All subjects < 250 CD4.
(5) Risk ratio.
(6) HR; CD4 250-349
(7) 0/8 treated subjects whose CD4 < 350. Risk Ratio.
(8) Risk ratio.
(9) HR; CD4 350-550

\section{Analysis 5.I. Comparison 5 Treated with ART vs Not Treated with ART (Female/Male Subgroup Analysis) (Observational Studies), Outcome I Incident HIV Infection.}

Review: Antiretroviral therapy for prevention of HIV transmission in HIV-discordant couples

Comparison: 5 Treated with ART vs Not Treated with ART (Female/Male Subgroup Analysis) (Observational Studies)

Outcome: I Incident HIV Infection

Study or subgroup $\quad \log [$ Risk Ratio $]$

Risk Ratio

Weight

Risk Ratio

(SE)

IV,Random,95\% Cl

IV,Random,95\% Cl

I Female Index Case

Del Romero 2010

$-3.5 \mid(1.27)$

$14.3 \%$

$0.03[0.00,0.36]$

Jia 2012

$-0.315(0.097702$ II)

Sullivan 2009 (I)

$-0.8(0.53)$

Subtotal $(95 \% \mathrm{CI})$

Heterogeneity: $\mathrm{Tau}^{2}=0.62 ; \mathrm{Chi}^{2}=7.04, \mathrm{df}=2(\mathrm{P}=0.03) ; \mathrm{I}^{2}=72 \%$

Test for overall effect: $Z=1.67(P=0.095)$

2 Male Index Case

Del Romero 2010

$-2.66(0.98)$

Jia 2012

$-0.288(0.09098851)$

Sullivan 2009 (2)

$-6.9 \mid(2.9)$

Subtotal $(\mathbf{9 5 \%}$ CI)

Heterogeneity: Tau $^{2}=3.91 ; \mathrm{Chi}^{2}=10.99, \mathrm{df}=2(\mathrm{P}=0.004) ; \mathrm{I}^{2}=82 \%$

Test for overall effect: $Z=1.60(P=0.11)$

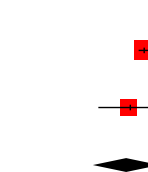

$50.4 \%$

$0.73[0.60,0.88]$

$35.3 \%$

$0.45[0.16,1.27]$

$00.0 \%$

$0.39[0.13,1.18$ ]

$37.9 \%$

$0.07[0.01,0.48]$

$47.1 \%$

$0.75[0.63,0.90]$

$15.0 \%$

$0.00[0.00,0.29]$

$100.0 \%$

$0.11[0.01,1.62$ ]

\section{$\begin{array}{lllll}0.01 & 0.1 & 1 & 10 & 100\end{array}$}

Favours experimental Favours control

Copyright (๑) 2013 The Cochrane Collaboration. Published by John Wiley \& Sons, Ltd. 
(I) Estimate is a rate ratio

(2) Estimate is a rate ratio.

Analysis 6.I. Comparison 6 Treated with ART vs Not Treated with ART (Subgroup Analysis: Low-/MiddleIncome vs High-income)) (Observational Studies), Outcome I Incident HIV Infection.

Review: Antiretroviral therapy for prevention of HIV transmission in HIV-discordant couples

Comparison: 6 Treated with ART vs Not Treated with ART (Subgroup Analysis: Low-/Middle-Income vs High-income)) (Observational Studies)

Outcome: I Incident HIV Infection

Study or subgroup log [Rate Ratio] Rate Ratio Reight Ratio

(SE) IV,Random,95\% Cl IV,Random,95\% Cl

$\begin{array}{lr}\text { I Low/Middle Income Country } & \\ \text { Birungi } 2012 & -0.0943(0.45) \\ \text { Donnell } 2010 & -2.53(\mathrm{I}) \\ \text { Jia } 2012(\mathrm{I}) & -0.301 \text { I } 05 \text { I }(0.065) \\ \text { Lu } 2010(2) & 0.363(0.27) \\ \text { Melo } 2008 & -2.33(1.45) \\ \text { Reynolds 20II } & -2.29(1.42) \\ \text { Sullivan 2009 } & -1.58(0.51)\end{array}$

Subtotal (95\% CI)

Heterogeneity: $\mathrm{Tau}^{2}=0.34 ; \mathrm{Chi}^{2}=21.43, \mathrm{df}=6(\mathrm{P}=0.002) ; \mathrm{I}^{2}=72 \%$

Test for overall effect: $Z=2.05(P=0.040)$

2 High Income Country
Del Romero 2010
$-1.58(1.48)$
Musicco 1994
$-0.13(0.46)$

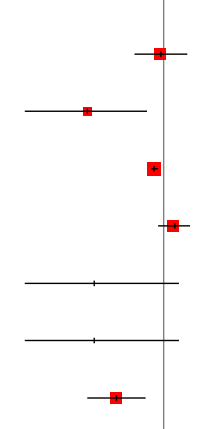

$17.7 \%$

$0.91[0.38,2.20]$

$7.1 \%$

$0.08[0.01,0.57]$

$28.0 \%$

$0.74[0.65,0.84]$

$23.3 \%$

$1.44[0.85,2.44]$

$3.9 \%$

$0.10[0.01,1.67]$

$4.1 \%$

$0.10[0.01,1.64]$

$16.0 \%$

$0.21[0.08,0.56]$

Subtotal (95\% CI)

Heterogeneity: $\mathrm{Tau}^{2}=0.0 ; \mathrm{Chi}^{2}=0.88, \mathrm{df}=\mathrm{I}(\mathrm{P}=0.35) ; \mathrm{I}^{2}=0.0 \%$

Test for overall effect: $Z=0.59(P=0.56)$

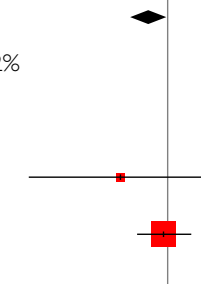

$100.0 \%$

0.53 [ 0.29, 0.97 ]

$8.8 \%$

$0.21[0.01,3.75]$

$91.2 \%$

$0.88[0.36,2.16]$

$100.0 \%$

0.77 [ $0.33,1.83$ ]

(1) Hazard Ratio

(2) Estimated from median follow-up time. 


\section{A P P E N D I C E S}

\section{Appendix I. Example of search strategy used in PubMed (modified as needed for use in the other databases)}

\begin{tabular}{|c|c|}
\hline Search & PubMed search strategy \\
\hline \#5 & Search (((\#16) AND \#17) AND \#18) AND \#19 Limits: Publication Date from 1987/01/01 to 2012/08/31 \\
\hline \#4 & $\begin{array}{l}\text { Search (randomised controlled trial[pt] OR controlled clinical trial[pt] OR randomised controlled trials[mh] OR random } \\
\text { allocation[mh] OR double-blind method[mh] OR single-blind method[mh] OR clinical trial[pt] OR clinical trials[mh] OR } \\
\text { "clinical trial" [tw]) OR ((singl*[tw] OR doubl*[tw] OR trebl*[tw] OR tripl*[tw]) AND (mask*[tw] OR blind*[tw])) OR } \\
\text { placebos[mh] OR placebo*[tw] OR random*[tw] OR non-randomi*[tw] OR before after study[tw] OR time series[tw] OR } \\
\text { "case control" [tw] OR prospective*[tw] OR retrospective*[tw] OR cohort[tw] OR cross-section*[tw] OR prospective[tw] } \\
\text { OR retrospective[tw] OR research design [mh:noexp] OR comparative study[mh] OR evaluation studies[mh] OR follow- } \\
\text { up studies[mh] OR prospective studies[mh] OR control*[tw] OR prospectiv*[tw] OR volunteer*[tw] OR longitud*[tw] } \\
\text { OR descripti*[tiab] OR study[tiab] OR evaluat*[tiab] OR "odds ratio"[tw] OR "hazard ratio"[tw] OR "relative risk" [tw] } \\
\text { OR "risk ratio" [tw] OR "rate ratio"[tw] OR AOR[tw] OR RRR[tw] OR NNT[tw]) }\end{array}$ \\
\hline
\end{tabular}

\#3 Search (Couples[tiab] OR (sex*[tiab] AND partner*[tiab]) OR husband[tiab] OR wife[tiab] OR boyfriend*[tiab] OR girlfriend*[tiab] OR spouse*[tiab] OR dyad*[tiab] OR married[tiab] OR marital[tiab] OR "Marriage"[Mesh] OR "Spouses"[Mesh] OR serodiscord*[tiab] OR sero-discord*[tiab] OR discord*[tiab])

\#2 Search (HAART[tiab] OR ART[tiab] OR ARV[tiab] OR ARVs[tiab] OR antiretroviral[tiab] OR anti-retroviral[tiab] OR anti-viral[tiab] OR antiviral[tiab] OR “Antiretroviral Therapy, Highly Active”[Mesh] OR “Anti-Retroviral Agents”[Mesh])

\#1 Search (HIV Infections[MeSH] OR HIV[MeSH] OR hiv[tiab] OR hiv-1[tiab] OR hiv-2*[tiab] OR hiv1[tiab] OR hiv2[tiab] OR hiv infect*[tiab] OR human immunodeficiency virus[tiab] OR human immune deficiency virus[tiab] OR human immuno-deficiency virus[tiab] OR human immune-deficiency virus[tiab] OR ((human immun*) AND (deficiency virus[tiab])) OR acquired immunodeficiency syndromes[tiab] OR acquired immune deficiency syndrome[tiab] OR acquired immuno-deficiency syndrome[tiab] OR acquired immune-deficiency syndrome[tiab] OR ((acquired immun*) AND (deficiency syndrome[tiab])) or "sexually transmitted diseases, viral”[mh]) OR HIV[tiab] OR HIV/AIDS[tiab] OR HIVinfected[tiab] OR HIV[title] OR HIV/AIDS[title] OR HIV-infected[title])

\section{Appendix 2. Search terms and yield in searching conference abstract archives}

It was not possible to perform complex searches of conference abstract archives. Instead, we used a variety of relevant terms, individually and in simple combinations.

AEGIS search strategy and results

Conferences included:

- British HIV/AIDS Association, 2001-2008

- Conference on Retroviruses and Opportunistic Infections (CROI), 1994-2008

- European AIDS Society Conference, 2001 and 2003

- International AIDS Society, Conference on HIV Pathogenesis, Treatment and Prevention (IAS), 2001-2005

- International AIDS Society, International AIDS Conference (IAC), 1985-2004

- US National HIV Prevention Conference, 1999, 2003, and 2005

Strategy:

(antiretroviral OR anti-retroviral) AND (discordant OR serodiscordant OR sero-discordant OR HIV-discordant)

Antiretroviral therapy for prevention of HIV transmission in HIV-discordant couples (Review)

Copyright @ 2013 The Cochrane Collaboration. Published by John Wiley \& Sons, Ltd. 
- total results: $\mathrm{n}=178$

- reviewed closely and excluded: $n=4$

- included: $\mathrm{n}=0$

IAC/IAS and CROI search terms and results:

- Discordant

- "HIV-discordant"

- Serodiscordant

- "Sero-discordant"

Previous version of review (searching IAC/IAS, 2006-2010; CROI, 2009-2011)

- total results: $\mathrm{n}=516$

- reviewed closely and excluded: $\mathrm{n}=0$

- included: $\mathrm{n}=0$

Current version of review (searching IAC 2012; CROI, 2012)

- total results: $\mathrm{n}=168$

- reviewed closely and excluded: $\mathrm{n}=0$

- included: $\mathrm{n}=2$ (One of these, Jia 2012, was subsequently published in a peer-reviewed journal, and we refer in this review to the published version.)

\section{Appendix 3. Newcastle Ottawa Quality Assessment Scale}

\section{COHORT STUDIES (Newcastle-Ottawa)}

Note: A study can be awarded a maximum of one star for each numbered item within the Selection and Outcome categories. A maximum of two stars can be given for Comparability

\section{Selection}

1) Representativeness of the exposed cohort

a) truly representative of the average treated serodiscordant couple in the community $\star$

b) somewhat representative of the average treated serodiscordant couple in the community $\star$

c) selected group of users eg nurses, volunteers, HIV clinic patients

d) no description of the derivation of the cohort

2) Selection of the non exposed cohort

a) drawn from the same community as the exposed cohort $\star$

b) drawn from a different source

c) no description of the derivation of the non exposed cohort

3) Ascertainment of exposure

a) secure record (eg surgical records) $\star$

b) structured interview $\star$

c) written self report

d) no description

4) Demonstration that outcome of interest was not present at start of study

a) yes $\star$

b) no

Comparability

1) Comparability of cohorts on the basis of the design or analysis

a) study controls for or matches on disease status when comparing treated and untreated couples $\star$

b) study controls for any additional factor ? (e.g. age or sex)

Outcome

1) Assessment of outcome

Antiretroviral therapy for prevention of HIV transmission in HIV-discordant couples (Review)

Copyright $\odot 2013$ The Cochrane Collaboration. Published by John Wiley \& Sons, Ltd. 

a) independent blind assessment $\star$
b) record linkage $\star$
c) self report
d) no description
2) Was follow-up long enough for outcomes to occur
a) yes (select an adequate follow up period for outcome of interest) $\star$
b) no
3) Adequacy of follow up of cohorts
a) complete follow up - all subjects accounted for $\star$
b) subjects lost to follow up unlikely to introduce bias - small number lost - > 79\% (select an adequate \%)
follow up, or description provided of those lost) $\star$
c) follow up rate $<20 \%$ (select an adequate $\%$ ) and no description of those lost
d) no statement

\section{NOS - CODING MANUAL FOR COHORT STUDIES}

\section{SELECTION}

1) Representativeness of the Exposed Cohort (NB exposure = intervention)

Item is assessing the representativeness of exposed individuals in the community, not the representativeness of the study sample from some general population. For example, subjects derived from groups likely to contain exposed people are likely to be representative of exposed individuals, while they are not representative of all people the community.

Allocation of stars as per rating sheet

\section{2) Selection of the Non-Exposed Cohort}

Allocation of stars as per rating sheet

3) Ascertainment of Exposure

Allocation of stars as per rating sheet

4) Demonstration That Outcome of Interest Was Not Present at Start of Study

In the case of mortality studies, outcome of interest is still the presence of a disease/ incident, rather than death. That is to say that a statement of no history of disease or incident earns a star.

A maximum of 4 stars can be allotted in Selection.

\section{COMPARABILITY}

\section{1) Comparability of Cohorts on the Basis of the Design or Analysis}

Either exposed and non-exposed individuals must be matched in the design and/or confounders must be adjusted for in the analysis. Statements of no differences between groups or that differences were not statistically significant are not sufficient for establishing comparability. Note: If the relative risk for the exposure of interest is adjusted for the confounders listed, then the groups will be considered to be comparable on each variable used in the adjustment.

A maximum of 2 stars can be allotted in this category.

\section{OUTCOME}

\section{2) Assessment of Outcome}

For some outcomes, reference to the medical record is sufficient to satisfy the requirement for confirmation. This may not be adequate for other outcomes where reference to specific tests or measures would be required.

a) Independent or blind assessment stated in the paper, or confirmation of the outcome by reference to secure records (health records, etc.)

b) Record linkage (e.g. identified through ICD codes on database records)

c) Self-report (i.e. no reference to original health records or documented source to confirm the outcome)

d) No description.

3) Was Follow-Up Long Enough for Outcomes to Occur

An acceptable length of time should be decided before quality assessment begins.

\section{4) Adequacy of Follow Up of Cohorts}

This item assesses the follow-up of the exposed and non-exposed cohorts to ensure that losses are not related to either the exposure or the outcome.

A maximum of 3 stars can be allotted in this category. 


\section{Appendix 4. Studies in progress}

There are a number of ongoing trials of Treatment as Prevention in Africa that are worth noting:

"MP3: An HIV Prevention Package for Mochudi" is a large, ongoing NIH-funded trial in Botswana of 14,000 men and women that will assess transmission on a community level as a result of a number of interventions (including education, behavior modification, circumcision, and use of ART). Results are expected in 2013.

"HIV VCT and Linkage to Care in Uganda" is a large NIH-funded trial in Uganda of 3,314 men and women that aims to estimate the impact of enhanced counseling and testing services on reducing HIV risk behavior. Furthermore, the trial will test whether an enhanced linkage to HIV-specific medical care is more effective than usual referral in receipt of ART and reducing mortality. Results are expected in 2013 .

"TasP Study"--a French National Agency for AIDS Research (ANRS) study (12249) is a trial in South Africa that aims to test 5000 people for HIV and offer approximately $750 \mathrm{HIV}$-positive individuals ARV treatment. In turn, the study will assess widespread HIV testing and prevention services in an immediate treatment arm versus a delayed treatment arm (according to CD4 level). The trial is scheduled to start in 2012.

"PopART: Population effects of antiretroviral therapy to reduce HIV transmission"-(HPTN 071) is a large trial proposed to be conducted across 24 communities in South Africa and Zambia. The intervention will be deployed to approximately 600,000 adults with 60,000 adults included in the evaluation cohort. The main objective is to measure the impact of immediate treatment, regardless of CD4, on HIV incidence when compared to treatment offerred according to the national guidelines. The protocol is currently in sponsor review process and results are expected in 2015.

\section{WHAT'S NEW}

Last assessed as up-to-date: 26 February 2013.

\begin{tabular}{l|ll}
\hline Date & Event & Description \\
\hline 26 February 2013 & $\begin{array}{l}\text { New citation required but conclusions have not } \\
\text { changed }\end{array}$ & Update. Conclusions not changed. \\
\hline 26 February 2013 & New search has been performed & $\begin{array}{l}\text { New searches and screening. Added two new observa- } \\
\text { tional studies }\end{array}$ \\
\hline
\end{tabular}

\section{H I S T O R Y}

Review first published: Issue 5, 2011

\begin{tabular}{l|ll}
\hline Date & Event & Description \\
\hline 8 October 2011 & Amended & Correction in regard to DSMB \\
\hline 8 August 2011 & New search has been performed & Toxicity and adverse events data added
\end{tabular}

Antiretroviral therapy for prevention of HIV transmission in HIV-discordant couples (Review) 
(Continued)

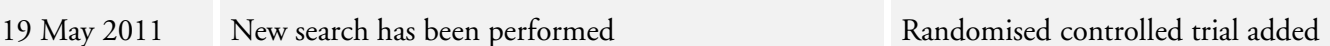

19 May 2011 New citation required and conclusions have changed Evidence of effect rated as high

\section{CONTRIBUTIONSOFAUTHORS}

All authors contributed to the design and conduct of this review, as well as with manuscript drafting and submission.

\section{DECLARATIONSOF INTEREST}

None known.

\section{SOURCES OF SUPPORT}

\section{Internal sources}

- Global Health Sciences, University of California, San Francisco, USA.

\section{External sources}

- World Health Organization, Switzerland.

- National Institute of Allergy and Infectious Diseases (NIAID), USA.

ME is supported by the National Institute of Allergy and Infectious Diseases (NIAID), Grant 5U01-AI069924-05.

\section{DIFFERENCES BETWEEN PROTOCOLANDREVIEW}

None.

NOT E S

None. 


\section{INDEX TERMS}

\section{Medical Subject Headings (MeSH)}

*Sexual Partners; Anti-HIV Agents [*therapeutic use]; CD4 Lymphocyte Count; Cohort Studies; HIV Infections [*prevention \& control; *transmission]; HIV Seronegativity; HIV Seropositivity [drug therapy; transmission]; HIV Serosorting

\section{MeSH check words}

Female; Humans; Male 